\title{
Runs of homozygosity in killer whale genomes provide a global record of demographic histories
}

\author{
Andrew D. Foote ${ }^{1,2,3 *}$ ( ) | Rebecca Hooper ${ }^{4 *}$ | Alana Alexander ${ }^{5}$ | Robin W. Baird ${ }^{6}$ | \\ Charles Scott Baker $^{7,8}$ | Lisa Ballance, ${ }^{7,9}$ | Jay Barlow ${ }^{9}$ | Andrew Brownlow ${ }^{10}$ | \\ Tim Collins $^{11}$ | Rochelle Constantine ${ }^{8}$ | Luciano Dalla Rosa ${ }^{12}$ | Nicholas J. Davison ${ }^{10}$ | \\ John W. Durban ${ }^{7,9}$ | Ruth Esteban ${ }^{13}$ | Laurent Excoffier ${ }^{3}$ | Sarah L. Fordyce Martin ${ }^{1}$ | \\ Karin A. Forney ${ }^{14,15}$ | Tim Gerrodette ${ }^{9}$ | M. Thomas P. Gilbert ${ }^{1,16}$ | Christophe Guinet $^{17}$ | \\ M. Bradley Hanson ${ }^{18}$ | Songhai Li ${ }^{19}$ | Michael D. Martin ${ }^{1}$ | Kelly M. Robertson' ${ }^{9}$ | \\ Filipa I. P. Samarra ${ }^{20}$ | Renaud de Stephanis ${ }^{13}$ | Sara B. Tavares ${ }^{21,22}$ () | Paul Tixier ${ }^{17,23}$ | \\ John A. Totterdell ${ }^{24}$ | Paul Wade ${ }^{25}$ | Jochen B. W. Wolf ${ }^{26}$ | Guangyi Fan²7,28,29 | \\ Yaolei Zhang ${ }^{27,30}$ | Phillip A. Morin ${ }^{9}$ (1) \\ ${ }^{1}$ Department of Natural History, NTNU University Museum, Norwegian University of Science and Technology (NTNU, Trondheim, Norway \\ ${ }^{2}$ Molecular Ecology and Fisheries Genetics Laboratory, School of Biological Sciences, Bangor University, Bangor, Gwynedd, UK \\ ${ }^{3} \mathrm{CMPG}$, Institute of Ecology and Evolution, University of Bern, Bern, Switzerland \\ ${ }^{4}$ University of Exeter, Penryn Campus, Penryn, Cornwall, UK \\ ${ }^{5}$ Department of Anatomy, School of Biomedical Sciences, University of Otago, Dunedin, New Zealand \\ ${ }^{6}$ Cascadia Research, Olympia, Washington, USA \\ ${ }^{7}$ Marine Mammal Institute, Oregon State University, Newport, Oregon, USA \\ ${ }^{8}$ School of Biological Sciences, University of Auckland, Auckland, New Zealand \\ ${ }^{9}$ Marine Mammal and Turtle Division, Southwest Fisheries Science Center, National Marine Fisheries Service, National Oceanographic and Atmospheric \\ Administration, La Jolla, California, USA \\ ${ }^{10}$ Scottish Marine Animal Stranding Scheme, Institute of Biodiversity, Animal Health \& Comparative Medicine, College of Medical, Veterinary \& Life Sciences, \\ University of Glasgow, Glasgow, UK \\ ${ }^{11}$ Ocean Giants Program, Wildlife Conservation Society, New York City, New York \\ ${ }^{12}$ Laboratório de Ecologia e Conservação da Megafauna Marinha, Instituto de Oceanografia, Universidade Federal do Rio Grande, Rio Grande, Brazil \\ ${ }^{13} \mathrm{CIRCE}$, Conservation, Information and Research on Cetaceans, Algeciras, Spain \\ ${ }^{14}$ Marine Mammal and Turtle Division, Southwest Fisheries Science Center, National Marine Fisheries Service, National Oceanic and Atmospheric \\ Administration, Moss Landing, California, USA \\ ${ }^{15}$ Moss Landing Marine Laboratories, San Jose State University, Moss Landing, California, USA \\ ${ }^{16}$ Section for Evolutionary Genomics, The GLOBE Institute, University of Copenhagen, Copenhagen, Denmark \\ ${ }^{17}$ UMR 7372 La Rochelle Université - CNRS, Centre d'Etudes Biologiques de Chizé (CEBC), Villiers-en-Bois, France \\ ${ }^{18}$ National Marine Fisheries Service, National Oceanic and Atmospheric Administration, Northwest Fisheries Science Center, Seattle, Washington, USA \\ ${ }^{19}$ Marine Mammal and Marine Bioacoustics Laboratory, Institute of Deep-Sea Science and Engineering, Chinese Academy of Science, Sanya, China \\ ${ }^{20}$ University of Iceland's Institute of Research Centres, Vestmannaeyjar, Iceland \\ ${ }^{21}$ Scottish Oceans Institute, East Sands, University of St. Andrews, St. Andrews, UK \\ ${ }^{22}$ Cetacean Research Program, Pacific Biological Station, Fisheries and Oceans Canada, Nanaimo, Canada \\ ${ }^{23}$ MARBEC Université de Montpellier-CNRS-IFREMER-IRD, Sète, France
}

${ }^{*}$ These authors contributed equally to this manuscript.

This is an open access article under the terms of the Creative Commons Attribution-NonCommercial License, which permits use, distribution and reproduction in any medium, provided the original work is properly cited and is not used for commercial purposes.

(c) 2021 The Authors. Molecular Ecology published by John Wiley \& Sons Ltd. 
${ }^{24}$ Cetacean Research Centre (CETREC WA, Esperance, Western, Australia

${ }^{25}$ National Marine Mammal Laboratory, National Marine Fisheries Service, National Oceanic and Atmospheric Administration, Alaska Fisheries Science Center, Seattle, Washington, USA

${ }^{26}$ Section of Evolutionary Biology, Department of Biology II, Ludwig Maximilian University of Munich, Planegg-Martinsried, Germany

${ }^{27}$ BGI-Qingdao, BGI-Shenzhen, Qingdao, China

${ }^{28}$ BGI-Shenzhen, Shenzhen, China

${ }^{29}$ China National GeneBank, BGI-Shenzhen, Shenzhen, China

${ }^{30}$ Translational Immunology group, Department of Biotechnology and Biomedicine, Technical University of Denmark, Lyngby, Denmark

Correspondence

Andrew D. Foote, Department of Natural

History, NTNU University Museum,

Norwegian University of Science and

Technology (NTNU), Trondheim, Norway.

Email: Andrew.Foote@ntnu.no

Phillip A. Morin, Marine Mammal and Turtle Division, Southwest Fisheries

Science Center, National Marine Fisheries

Service, National Oceanographic and

Atmospheric Administration, La Jolla,

California, USA.

Email: Phillip.Morin@noaa.gov

\section{Funding information}

Schweizerischer Nationalfonds zur

Förderung der Wissenschaftlichen

Forschung, Grant/Award Number:

31003A-143393; European Science

Foundation-Research Networking

Programme ConGenOmics, Grant/

Award Number: Short Visit Grant; H2O2O

European Research Council, Grant/Award

Number: 681396-Extinction Genomics

COG; H2020 Marie Skłodowska-Curie

Actions, Grant/Award Number: 663830

\begin{abstract}
Runs of homozygosity ( $\mathrm{ROH}$ ) occur when offspring inherit haplotypes that are identical by descent from each parent. Length distributions of $\mathrm{ROH}$ are informative about population history; specifically, the probability of inbreeding mediated by mating system and/or population demography. Here, we investigated whether variation in killer whale (Orcinus orca) demographic history is reflected in genome-wide heterozygosity and $\mathrm{ROH}$ length distributions, using a global data set of 26 genomes representative of geographic and ecotypic variation in this species, and two F1 admixed individuals with Pacific-Atlantic parentage. We first reconstructed demographic history for each population as changes in effective population size through time using the pairwise sequential Markovian coalescent (PSMC) method. We found a subset of populations declined in effective population size during the Late Pleistocene, while others had more stable demography. Genomes inferred to have undergone ancestral declines in effective population size, were autozygous at hundreds of short $\mathrm{ROH}(<1 \mathrm{Mb})$, reflecting high background relatedness due to coalescence of haplotypes deep within the pedigree. In contrast, longer and therefore younger $\mathrm{ROH}(>1.5 \mathrm{Mb}$ ) were found in low latitude populations, and populations of known conservation concern. These include a Scottish killer whale, for which $37.8 \%$ of the autosomes were comprised of $\mathrm{ROH}>1.5 \mathrm{Mb}$ in length. The fate of this population, in which only two adult males have been sighted in the past five years, and zero fecundity over the last two decades, may be inextricably linked to its demographic history and consequential inbreeding depression.
\end{abstract}

\section{KEYWORDS}

Runs of Homozygosity, Demography, killer whale, Orcinus orca, whole genome sequencing, inbreeding

\section{1 | INTRODUCTION}

Species ranges change in response to environmental oscillation (Foote et al., 2013; Lorenzen et al., 2011), and rapid shifts can currently be observed during ongoing global warming (Chen et al., 2011; Parmesan \& Yohe, 2003). Understanding how range shifts influence the genetic diversity of natural populations at the range edge is an increasingly important conservation consideration (Excoffier et al., 2009; see North et al., 2021 this issue). The changes in genetic diversity experienced by populations during the climatic change and warming following the Last Glacial Maximum (LGM) offer a window into potential future changes due to ongoing global warming (Lorenzen et al., 2011; Foote et al., 2013; Louis et al., 2020; Nykänen et al., 2019).

Whilst summary statistics of genetic diversity can provide a useful metric of the impact of demography, it can be difficult to attribute these metrics to specific past demographic changes or events (although site frequency spectra contain much information; Excoffier et al., 2013; Gutenkunst et al., 2009; Sousa \& Hey, 2013). The increasing use of whole genome sequencing (WGS) in molecular ecology, as showcased in this special issue of Molecular Ecology, is providing unprecedented resolution of population demographic 
and evolutionary history in an increasingly broad range of nonmodel organisms (e.g. Sarabia et al., 2021). This is due to the increased accuracy in the inference of timing of demographic events being drawn from the contiguity, distribution and linkage between loci afforded by WGS data sets (Leitwein et al., 2020; Veeramah \& Hammer, 2014). The coalescence times of identical by descent haplotypes inherited from both parents, which form runs of homozygosity $(\mathrm{ROH})$, can provide such insights into past demography and more recent inbreeding (Brüniche-Olsen et al., 2018; Ceballos et al., 2018; Kardos et al., 2016). ROH can be broken up by subsequent generations of outbreeding, thus the distribution of lengths of $\mathrm{ROH}$ across the genome reflects local recombination rate, demographic history (contemporary and ancestral effective population size and thus the rate of coalescence through time), migration rate, and mating behaviour (Ceballos, Joshi, et al., 2018; Kardos et al., 2016).

In this study, we showcase how patterns of coalescence in individual representative genomes sampled from multiple populations, can be used to reconstruct global variation in demographic histories among killer whale (Orcinus orca) populations. Killer whales are comparable to humans in their global distribution, having colonised all the major oceans (Forney \& Wade, 2006). Killer whale occurrence is correlated with ocean productivity; highest densities are therefore at high latitudes, decreasing by 1-2 orders of magnitude from the Arctic and Antarctic to the tropics (Figure S1; Forney \& Wade, 2006; Morin et al., 2015). The northern and southern extremes of this range were covered by ice sheets during the Last Glacial Maximum (Figure S1; Morin et al., 2015) and must therefore have been colonised through range expansion from lower latitudes in the last 16,000 years (Foote et al., 2019; Hoelzel et al., 2007; Morin et al., 2015). Post-glacial range expansions in different ocean basins offer the possibility to explore the genetic outcomes of independent, parallel demographic histories. Killer whales thus represent a useful system for studying the relationship between demographic history and genetic diversity.

\section{2 | MATERIALS AND METHODS}

\subsection{Data set}

Our primary genomic data set consisted of 26 genomes from samples selected to best represent the known global geographic and genetic diversity of this species (Figure 1; Foote et al., 2019). In addition to previously published, low-coverage whole genome sequence data, new paired-end libraries were built from 20 of the samples using the BEST library build method (Carøe et al., 2018) from genomic DNA that was sheared to an average size of $350-550$ bp using a Covaris ME220. Libraries were subsequently dual indexed and amplified for 12 cycles, then purified using ampure beads (Agilent Technologies). The DNA concentration of the libraries was measured using an Agilent TapeStation (Agilent Technologies); these were then equimolarly pooled and sequenced across eight lanes of an Illumina HiSeq4000 platform. An additional two genomes from captive killer whales with mixed parentage of Icelandic mothers and a North Pacific transient father were generated as above, with the following differences in protocols. Genomic DNA was sheared to an average size of $\sim 500$ bp using a Diagenode Bioruptor Pico sonication device. The sheared DNA extracts were converted to blunt-end Illumina sequencing libraries as above. Libraries were subsequently dual indexed and amplified for 12 cycles using a KAPA HiFi HotStart PCR kit (Kapa Biosystems) in $50 \mu$ reactions following the manufacturer's guidelines and sequenced on one lane of an Illumina HiSeq4000 platform.

Reads from each individual were processed with AdapterRemoval2 (Schubert et al., 2016) to trim residual adapter sequence contamination and to remove adapter dimer sequences as well as low-quality $(\mathrm{Q}<30)$ stretches at the read ends. Filtered reads $>30$ bp were then mapped using BWA-MEM algorithm to a highquality, chromosomal O. orca reference assembly (Zhang et al., 2021), requiring a mapping quality greater than 30 . Clonal reads were collapsed using the markdup function of the samtools (Li et al., 2009).

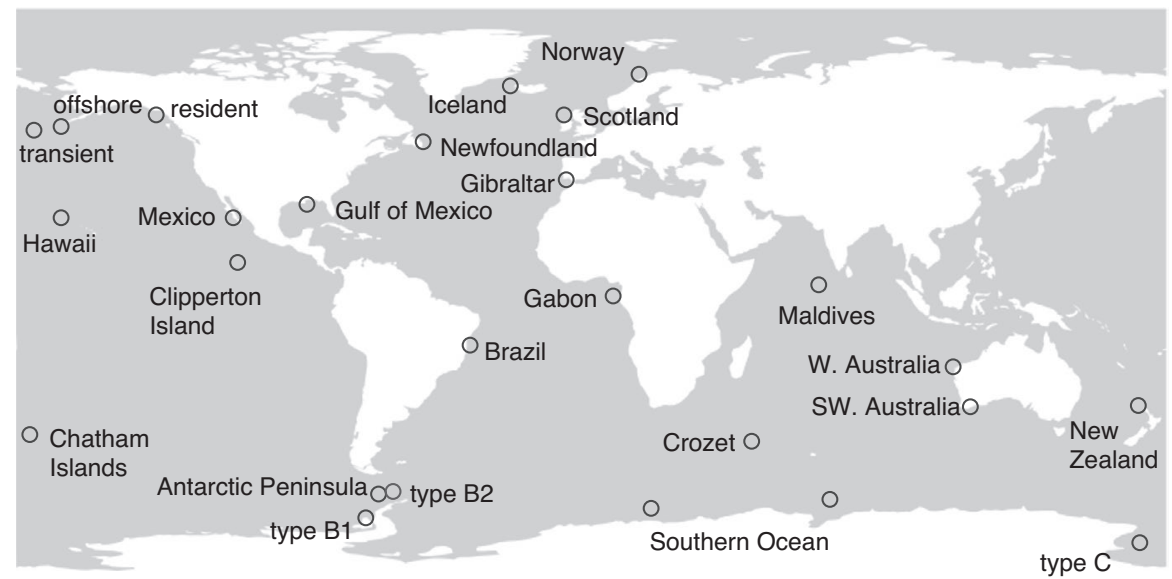

FIGURE 1 Map of sampling locations of the genomes included in this study. Note that sample names used in this study do not necessarily denote discrete populations or geographic/political entities: for example, Norway and Iceland samples appear to belong to the same metapopulation; Chatham Islands is a part of New Zealand but different names are used to distinguish between the two samples labelled New Zealand and Chatham Islands, which have distinct ancestry (Foote et al., 2019) etc 
Repetitive elements were identified using repeatmasker (Smit et al. 1996) and the Cetartiodactyl repeat library from repbase (Kohany et al., 2006), and masked using bedtools (Quinlan \& Hall, 2010). Sites were further filtered to include only autosomes.

\subsection{Estimating theta $(\theta)$ from individual genomes}

To understand the impact of ancestral demography on contemporary killer whale populations, we estimated variation in heterozygosity among our global data set of individuals. We estimated heterozygosity of autosomal regions from individual diploid genomes. Under the infinite sites model (Kimura, 1969), individual heterozygosity is a good, unbiased estimator of the population mutation rate, theta ( $\theta$; Watterson, 1975). Theta was estimated directly from the filtered bam files using the maximum likelihood estimator (Lynch, 2008) implemented in MLRHO v.2.9. (Haubold et al., 2010).

\subsection{Estimating changes in effective population size $\left(N_{\mathrm{e}}\right)$ through time from individual genomes}

Changes in $N_{e}$ through time were inferred using the pairwise sequential Markovian coalescent (PSMC) (Li \& Durbin, 2011), a method suitable for studying ancient demographic history from a single unphased genome per population. The PSMC model estimates the time to most recent common ancestor (TMRCA) of segmental blocks of the genome and uses information from the rates of the coalescent events to infer $N_{e}$ at a given time, thereby providing a direct estimate of the past demographic changes of a population ( $\mathrm{Li}$ \& Durbin, 2011). We selected the highest coverage genomes, building a consensus sequence of each bam file in fastq format sequentially using: first, SAMTOOLS mpileup command with the -C50 option to reduce the effect of reads with excessive mismatches; second, BCFTOOLs view -c to call variants; lastly, vcfutils.pl vcf2fq to convert the vcf file of called variants to fastq format with further filtering to remove sites with less than a third or more than double the average depth of coverage and Phred quality scores $<30$. The PSMC inference was then carried out using the recommended input parameters for human autosomal data, that is, 25 iterations, with maximum $\operatorname{TMRCA}\left(T_{\max }\right)=15$, number of atomic time intervals $(n)=64$ (following the pattern $\left(1^{*} 4+25^{*} 2+1^{*} 4+1^{*} 6\right)$, and initial theta ratio $(r)=5$. Plots were scaled to real time as per Foote et al. (2016) assuming a generation time of 25.7 years and a neutral autosomal mutation rate of $2.34 \times 10^{-8}$ substitutions per nucleotide per generation. For depth of coverage $<20 \times$, negative false detection of heterozygote sites can produce the same effect as a lower mutation rate would have on the plot, causing shifts both along the $x$ - and $y$-axes (for example see Figure S10 of Foote et al., 2016). Based on the overlap in our plots, and the uncertainty on which false negative detection rate to apply, we did not apply the uniform correction factor option in PSMC to account for small variations in coverage between our genomes. However, to better understand the impact of coverage on PSMC plot trajectory, we extended the tests run in Foote et al. (2016) by estimating demographic parameters using PSMC on a randomly downsampled (0.1-0.9 $\times$ of total coverage, in $0.1 \times$ increments) high coverage ( $>20 \times$ mean effective coverage) genome.

\subsection{Calling runs of homozygosity}

Runs of homozygous genotypes were identified using the windowbased approach implemented in PLINK v1.07 (Purcell et al., 2007). Genotypes were called concurrent to estimating genotype likelihoods for all samples simultaneously, both using ANGSD (Korneliussen et al., 2014), estimating the posterior genotype probability based on the allele frequency as a prior, inferring the major and minor allele from genotype likelihoods, and only outputting SNPs at sites that were identified as polymorphic with likelihood ratio test $p$-values of $<.000001$ and with a minimum minor allele frequency of 0.05 . This resulted in two output files, one of called genotypes in T-ped format to be used as input for PLINK, the second of genotype likelihoods in BEAGLE format (Browning \& Browning, 2007), for example, likelihoods of the three possible genotypes: AA, Aa and aa, for each inferred biallelic SNP in each individual and normalised so that the likelihood for all three possible genotypes summed to one. The called genotypes in T-ped format and normalised genotype likelihoods in Beagle format were compared to assess confidence in the PLINK input file. Additional filtering steps used during the calling of SNPs were the removal of reads of poor mapping quality (MAPQ $<30$ ), removing sites with low base quality scores ( $q<20$ ), discarding reads that did not map uniquely, adjusting q-scores around indels, adjusting minimum quality score to 50 for excessive mismatches, and discarding bad reads (flag $\geq 256$ ). Inferred SNPs were lightly pruned based on linkage disequilibrium (LD) $r^{2}>0.9$ using PLINK, which has been found to improve the accuracy of detecting autozygous ROHs (Howrigan et al., 2011). We estimated ROH from pruned and unpruned data and found minimal qualitative difference with our data, and therefore proceeded with unpruned data. Sliding window size was set to $300 \mathrm{~kb}$, with a minimum of 50 SNPs at a minimum density of $1 \mathrm{SNP}$ per $50 \mathrm{~kb}$ required to call a $\mathrm{ROH}$. To account for genotyping errors, we allowed up to 3 heterozygote sites per $300 \mathrm{~kb}$ window within called ROHs, as per Ceballos et al. (2018). A length of $1000 \mathrm{~kb}$ between two SNPs was required in order for them to be considered in two different ROHs. Our command line was as follows:./plink --tfile chr1 --homozyg-snp 50 --homozyg-kb 300 --homozyg-density 50 --homozyg-gap 1000 --homozyg-window-snp 50 --homozyg-window-het $3 \quad$--homozyg-window-missing 10 --homozyg-window-threshold 0.05 --out chr1.

\section{3 | RESULTS}

\section{1 | Genome sequences}

Previously published short-read data sequenced to $\sim 5 \times$ effective coverage (depth of sequencing post QC filtering) of the autosomal 
region of the killer whale genome (Foote et al., 2019) were combined with published data from a Norwegian (Foote et al., 2015) and Pacific resident killer whale (Moura et al., 2014) and an additional eight lanes of a HiSeq4000 sequencing to increase samples to $10-20 \times$ effective coverage (i.e., post-QC filtering). Additionally, two F1 mixed ancestry captive killer whales with Icelandic and Pacific transient parentage were also sequenced across one lane of a HiSeq4000 to a mean of $5 \times$ coverage. In total, the data set comprised 23 genomes sequenced to between 10-20x mean depth of coverage, and five samples sequenced to $\sim 5 \times$ mean depth of coverage. All depth of coverage estimates are based on bam files for which duplicate reads, low quality mapping regions and repeats have been masked and all filtering steps completed. Distribution of effective depth of coverage for each sample is shown in Figure S2, and distribution of base quality scores for all filtered data is shown in Figure S3. All raw sequencing data used in this study are publicly archived under the Orcanomics BioProject (NCBI accession: PRJNA531206), with the exception of the reads of the Norwegian and Alaskan resident killer whales, which are archived under NCBI BioProjects PRJNA167475 and PRJNA236163 respectively. A complete table of BioProject, BioSample and SRA accession numbers are provided in Table S1.

\subsection{Impact of variation in depth of coverage}

Due to the variation in coverage among samples, we down-sampled from a high-coverage genome assembly (Foote et al., 2015) to investigate the impact upon our estimates of $\theta$, inference of $N_{e}$ through time using PSMC, and our calls of $\mathrm{ROH}$ (Figure S4). We found that estimates of $\theta$ by mIRho showed a moderate nonlinear decline with decreasing depth of coverage (Figure S4c). Our inferred PSMC trajectories of a downsampled Norwegian killer whale genome were qualitatively similar down to half of the reads being subsampled (corresponding to approximately a mean depth of coverage of $10 x$ ), but at lower rates of subsampling, plots showed stronger deviation along both the $x$ - and $y$-axes (Figure S4d). Our estimates of the number and sum of $\mathrm{ROH}>0.3 \mathrm{Mb}$ in length were relatively consistent down to $0.3 \times$ the total number of reads being downsampled (Figure S4e). Therefore, we report theta estimates and present PSMC plots only for samples with effective depth of coverage $>10 \times$, but report $\mathrm{ROH}$ estimates for all samples.

\subsection{Estimates of theta $(\theta)$ from individual genomes}

Counterintuitive to the conventional view of genetic diversity, the lowest estimates of $\theta$ were found in high latitude populations, that is, in the regions with the greatest habitat suitability and highest density of present-day killer whales, for example, Alaskan resident ecotype, Antarctic types B1, B2 and C, Norway and Scotland (Figure S1; Table S2). However, some of these regions were not suitable habitat for killer whales during the Last Glacial Maximum (Figure S1).

\subsection{Pairwise sequential Markovian coalescent inference of ancient ( $>10,000$ years ago) demographic histories}

We found that the PSMC plots broadly followed one of three trajectories of changes in $N_{e}$ through time (Figure 2). Each of these trajectories was shared among a subset of several individuals. The segregation of genomes based upon PSMC plot trajectory approximately corresponds to the segregation along the major axis of structure detected in PCA and individual assignment (NGSadmix) analyses (Foote et al., 2019). The genomes for which PSMC inferred a decline in $\mathrm{N}_{\mathrm{e}}$ during the last glacial period were intuitively the same as those with markedly lower $\theta\left(=4 N_{\mathrm{e}} \mu\right)$ estimated by MLRHO (Table S2).

Qualitatively similar demographic histories previously inferred from the Norwegian and North Pacific resident ecotype genomes using PSMC (Foote et al., 2016; Moura et al., 2014) were also shared with a geographically widespread set of Pacific and Atlantic samples (Figure 2a). The point at which PSMC plots become identical can be an indication of the point in time at which alleles in each genome coalesce within a shared ancestral population (Mather et al., 2020). However, as the rate of cross coalescence is not tested in PSMC, this could also reflect similar but independent coalescent processes in each individual's demographic histories, and therefore similar rates of coalescence in each individual's genome.

The second pattern observed in the PSMC plots (Figure 2b) encompassed a wide geographically distributed set of samples, which share much of the trajectory in $N_{\mathrm{e}}$ through time with the plots in Figure 2A, but remain stable or increase at $\sim 40,000$ years BP. The plots then separate and show distinct trajectories roughly 10,000 years either side of the LGM. Note that the time calibration in all of these PSMC plots is dependent upon the accuracy of the mutation rate and generation time estimates, so should not be interpreted too literally, but rather as a broad indication of the temporal scale of events.

The third pattern of inferred changes in $N_{e}$ through time was shared among the Antarctic morphotypes: types B1, B2 and C (Figure 2c). We infer a longer-term low $N_{e}$ in the genealogical ancestors of these three genomes compared to the apparent baseline effective population size $\left(N_{\mathrm{e}} \approx 0.5 \times 10^{4}\right)$ inferred in most other genomes included in this study. A shared demographic history which includes extensive genetic drift has previously been inferred from the high covariance in allele frequencies shared among these three Antarctic types, and their strong genetic differentiation from all other killer whale populations (Foote et al., 2016, 2019). The timing of inferred changes in $\mathrm{N}_{\mathrm{e}}$ (Figure 2c) correspond closely to timing of cross coalescence due to admixture and divergence visualised in Figure $3 c$ and d of Foote et al. (2019).

The genome from a "type A" killer whale sampled off the tip of Antarctic Peninsula had a unique demographic history, among our data set, inferred by PSMC. Inferred $N_{e}$ increased exponentially by two orders of magnitude between $\sim 200,000$ years ago and 20,000 years ago. The sudden inferred exponential increase in the plot resembles PSMC plots of unphased pseudo-diploid genomes 
(a)

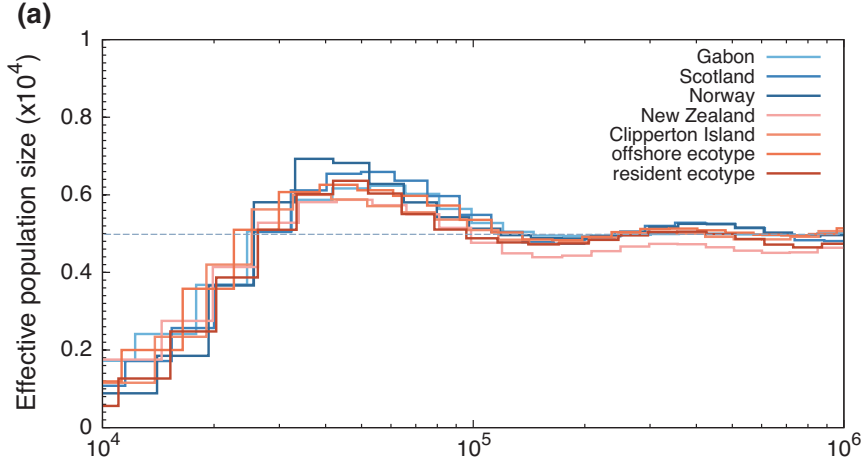

(c)

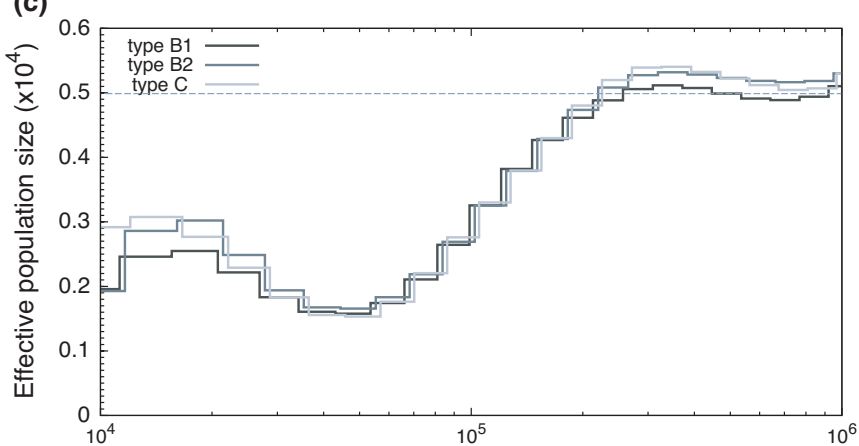

(b)

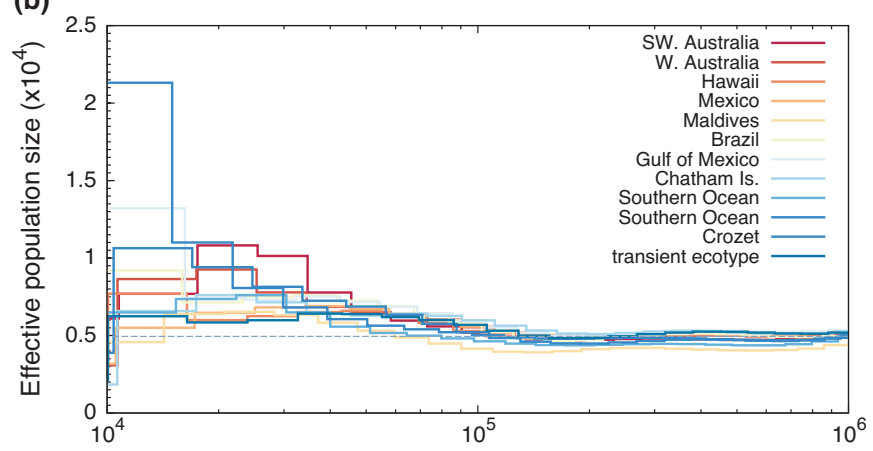

(d)

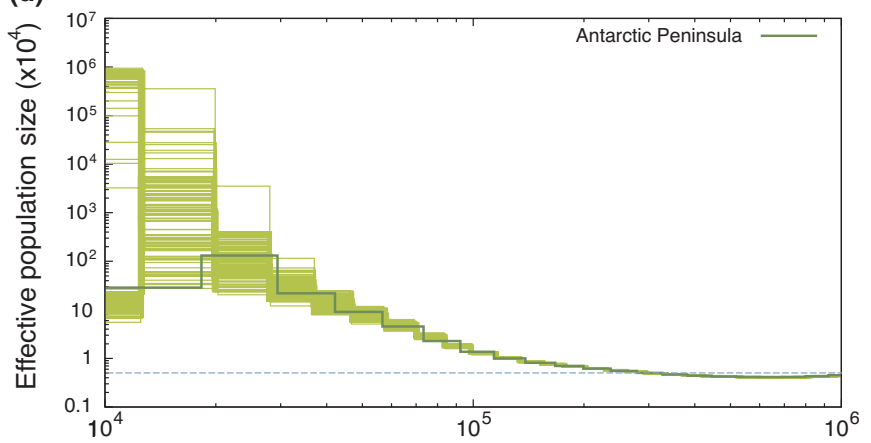

Years before present (assuming a generation time of 25.7 years and mutation rate $(\mu)$ of $2.34 \times 10^{8}$ substitutions per nucleotide per generation)

FIGURE 2 Pairwise sequentially Markovian coalescent (PSMC) plots of changes in effective population size $\left(N_{\mathrm{e}}\right)$ through time inferred from coalescence rates across individual genomes. (a) PSMC plots for the genomes of Atlantic (blue) and Pacific (red) killer whales, which show a similar trajectory. (b) PSMC plots for the genomes of a geographically widespread subset of killer whales, which show a similar stable trajectory until $\sim 30,000$ years ago. (c) PSMC plots for one genome each of an Antarctic type B1, Antarctic type B2 and Antarctic type C killer whale, which show a similar trajectory until the Last Glacial Maximum (LGM). (d) PSMC plot inferred from the genome of an Antarctic type A killer whale sampled off the Antarctic Peninsula. The thick line represents the median. Due to the unusually high estimate of $N_{e}$ in plot (d), we chose to visualise uncertainty around the median, and thin lines correspond to 100 rounds of bootstrapping. Note that the $y$ axis has a logarithmic scale in plot (d). Each plot has a horizontal dashed line drawn at $0.5 \times 10^{4}$ to facilitate visual comparison between the different plots

generated by combining two randomly sampled haploid genomes from two different individuals, in which the upsweep can be coarsely indicative of the timing of cessation of cross coalescence after populations diverge (Cahill et al., 2016). Similar PSMC patterns are reported by Sarabia et al. in this special issue, for an Egyptian African golden wolf (Canis lupaster), with apparent introgressed ancestry (Sarabia et al., 2021). QC checks performed when combining the sequencing data generated in 2016 and 2021 for each individual included randomly selecting an allele from each site of the genome for filtered bam files corresponding to the 2016 and 2021 data, and then estimating covariance between the 2016 and 2021 sequencing data for the same individual (to test for batch effects). We found high covariance between alleles randomly drawn from the 2016 and 2021 sequence data for all other individuals. However, the covariance of randomly drawn alleles from the 2016 and 2021 batches of data for the Antarctic Peninsula sample was similar to random draws from different individuals. This could be consistent with either contamination of one of the sequence runs for this sample, or unusually high genetic diversity in this individual. We further checked for signs of contamination of sequencing data for this individual by comparing the haploid mitochondrial genome sequence, both between
2016 and 2021 data, and with earlier published targeted sequencing the of the mitogenome (Morin et al., 2010, 2015). The mitogenome sequence was haploid and consistent across sequencing data sets, suggesting this high genetic diversity in the nuclear genome was not an artefact of contamination during sequencing. We therefore interpret the PSMC plot of the Antarctic Peninsula killer whale as evidence that this individual has admixed ancestry comprised of two distinct genetic backgrounds.

\subsection{Calling runs of homozygosity}

In total, 3,960,271 SNPs were called from the repeat-masked, QC filtered autosomes. The mean inverse SNP density (Kb per SNP) was 0.642 (range: $0.204-4.906$; Figure S5), that is, on average there was a physical distance of $642 \mathrm{bp}$ between SNPs. The mean number of SNPs per ROH was 1,310 (range: 69-55,309; Figure S5). As we only consider $\mathrm{ROH}$ of length $\geq 0.3 \mathrm{Mb}$, a called $\mathrm{ROH}$ would, based on the average SNP densities, require calling homozygous genotypes at approximately $>467$ consecutive SNPs. We found that increasing the number of missing windows (--homozyg-window-missing) increased 
the number of $\mathrm{ROH}$ called in the lower coverage $(<10 x)$ genomes, which plateaued at 30 missing sites per 300,000 bp window (i.e., allowing windows to be called as $\mathrm{ROH}$ when there is $\leq 0.01 \%$ missing data). There was no difference in the $\mathrm{ROH}$ of higher coverage $(>10 \times)$ genomes above 10 missing sites per window.

\section{6 | ROH density}

$\mathrm{ROH}$ density along chromosome 1 highlights the overlap in $\mathrm{ROH}$ among the genomes (Figure 3). $\mathrm{ROH}$ in up to 17 genomes overlapped at some $100-\mathrm{kb}$ windows along chromosome 1 , with a mean $\mathrm{ROH}$ density of 8.3 overlapping ROH per 100-kb window (when considering only windows with at least one $\mathrm{ROH}$ ). In particular, $\mathrm{ROH}$ overlapped in those genomes that showed a similar decline in $\mathrm{N}_{\mathrm{e}}$ during the last glacial period as represented in Figure 2a. However, this does not necessarily signify shared IBD tracts due to recent shared ancestry among genomes. When we estimated pairwise genetic distance based upon IBS (identical by state) across all genomes at sites within $\mathrm{ROH}$ in the Norwegian killer whale genome, only the closely related Icelandic killer whale clustered by IBS with the Norwegian killer whale, and therefore probably share identical $\mathrm{ROH}$ tracts through descent from a common ancestor (Figure S6). Variation in $\mathrm{ROH}$ density therefore probably reflects variation in recombination rate along the genome (as per Kardos et al., 2017).

\section{7 | Sum and number of ROH within individual genomes}

The sum and number of $\mathrm{ROH}$ (SROH and $\mathrm{NROH}$ respectively) within individual genomes were intuitively highly correlated (Spearman correlation $\rho=0.91, p=1.3 \times 10^{-6}$; Figure 4). The $\mathrm{SROH}$ and $\mathrm{NROH}$ are expected to reflect population demography (Ceballos, Joshi, et al., 2018). Large populations are expected to have low SROH and $\mathrm{NROH}$, which will be further reduced by admixture; in particular admixture between highly diverged lineages carrying different haplotypes will reduce the number and sum of $\mathrm{ROH}$ in the genome (Ceballos, Joshi, et al., 2018). In contrast, populations that have experienced population bottlenecks will have higher $\mathrm{SROH}$ and $\mathrm{NROH}$ (Ceballos, Joshi, et al., 2018). Qualitatively similar ROH length distributions were observed among individuals from high latitude populations in different ocean basins, which were inferred using PSMC to have undergone through a decline in $N_{\mathrm{e}}$ during the last glacial period

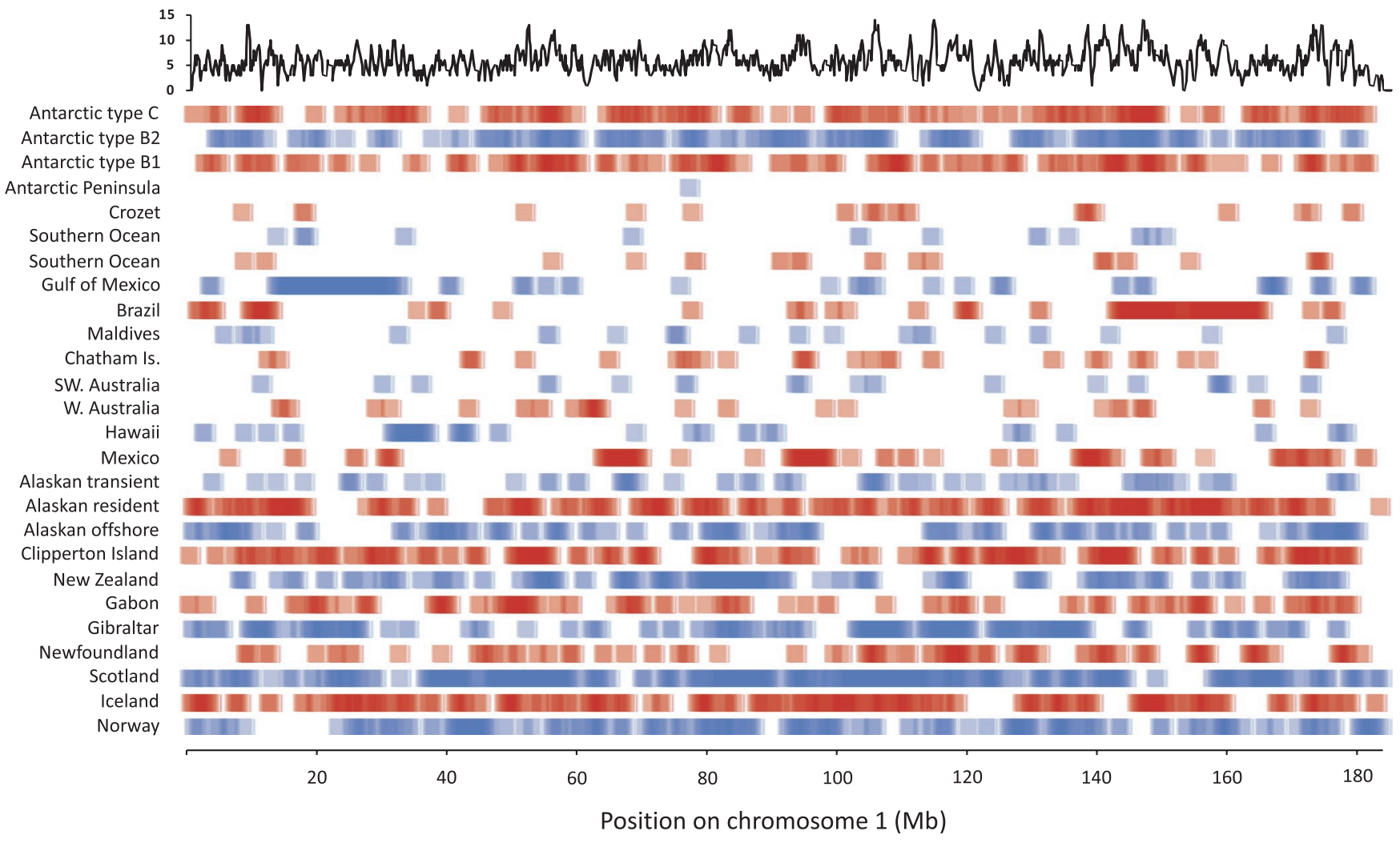

FIGURE 3 Physical mapping of ROH density along chromosome 1 of all ROH $>0.3 \mathrm{Mb}$ in 26 globally sampled killer whale genomes. The top panel shows counts of overlapping $\mathrm{ROH}$ in nonoverlapping 100-kb windows for all 26 genomes. The bottom panel presents ROH density per individual genome. Each $100-\mathrm{kb}$ window containing a $\mathrm{ROH}$ is shaded red and blue in alternating rows. Genomes are ordered so that those in different panels in Figure 2 are grouped together, for example, the first three rows are Antarctic types for which a long-term low $N_{e}$ was inferred; row 4 is the admixed Antarctic Peninsula genome, with just a single ROH in chr1, etc 


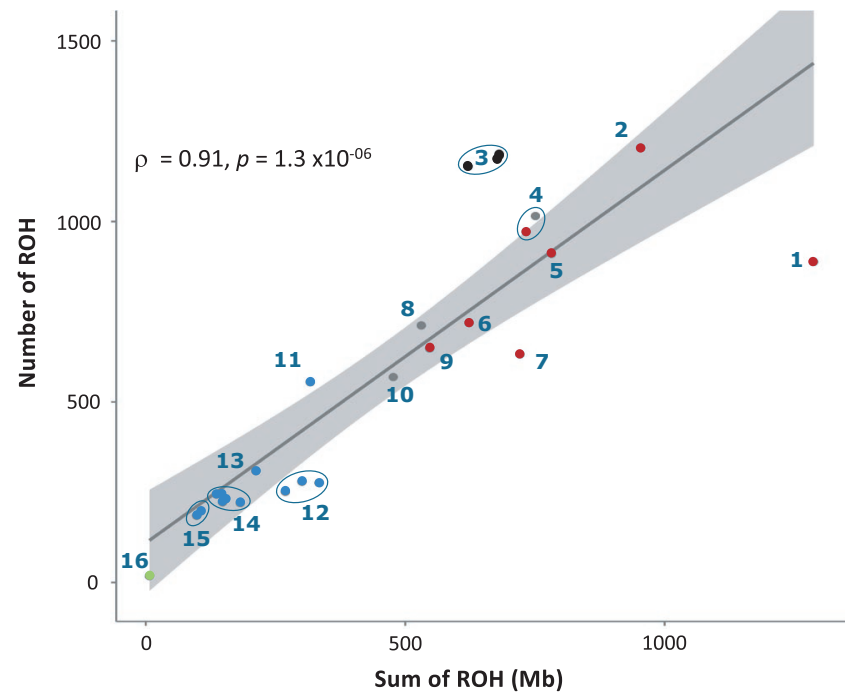

FIG URE 4 Number of ROH compared to the sum of the length of $\mathrm{ROH}$ across the autosomes. Data points are coloured by PSMC trajectory; those genomes included in Figure $2 \mathrm{a}$ are coloured red, those in Figure $2 \mathrm{~b}$ are coloured blue, those in Figure $2 c$ are coloured black, and the admixed Antarctic Peninsula type A individual in Figure $2 d$ is coloured green. The lower coverage genomes not included in the PSMC analyses are coloured grey. Numbered data points indicate genomes from the following populations/locations: 1. Scotland, 2. Alaskan resident ecotype, 3. Antarctic types B1, B2 and C, 4. Norway and Iceland, 5. Eastern Tropical Pacific (ETP) - Clipperton Island, 6. Alaskan offshore ecotype, 7. New Zealand, 8. Gibraltar, 9. Gabon, 10. Newfoundland, 11. Alaskan transient ecotype, 12. Crozet, Brazil and Gulf of Mexico, 13. Chatham Islands, 14. Hawaii, ETP - Mexico, W. Australia, Southern Ocean and Maldives, 15. SW. Australia and Southern Ocean, 16. Antarctic Peninsula

(Figure 2a,c; Figure S7). In this subset of genomes, autozygosity was spread across hundreds of short (less than $1 \mathrm{Mb}$ in length) $\mathrm{ROH}$ (Figures 3, 4, 5a; Figure S7).

Deviation from the regression line can be informative (assuming equivalent recombination rates) as to whether demographic history (contemporary and ancestral $N_{\mathrm{e}}$ ), or mating behaviour, or a combination, are factors in determining the length distribution of $\mathrm{ROH}$ across the genome (Ceballos, Joshi, et al., 2018). For example, Antarctic types B1, B2 and C have an excess of smaller $\mathrm{ROH}$, suggesting a high rate of out-breeding relative to populations along the regression line. The genome of a female from the "West Coast Community" of killer whales of Scotland was a marked outlier below the regression line, indicating an excess of long $\mathrm{ROH}$ relative to populations along the regression line; consistent with consanguineous mating and long-term low $\mathrm{N}_{\mathrm{e}}$.

\section{8 | Inferring approximate TMRCA of $\mathrm{ROH}$ of differing length}

Since homozygous tract length $(L)$ declines as a function of recombination rate $(r)$ and time $(t)$, $\mathrm{ROH}$ due to background inbreeding during an ancestral bottleneck are expected to be shorter than $\mathrm{ROH}$ caused by recent inbreeding (Kardos et al., 2017). The expected length of $\mathrm{ROH}$ is $L=100 / 2 \mathrm{t} \mathrm{cM}$, where $t$ is the time back to the parental common ancestor in generations (Thompson, 2013). So that for example, 0.5 $\mathrm{Mb} \mathrm{ROH}$, which we found are common in some high latitude populations, would correspond to two IBD tracts coalescing in a parental common ancestor $\approx 88$ generations ago (assuming a recombination rate, $r$, equivalent to that in humans, $1.133 \mathrm{cM} / \mathrm{Mb}$; Dumont \& Payseur, 2008), which equates to 2270 years ago (assuming a generation time of 25.7 years; Taylor et al., 2007). However, it should be noted that mendelian sampling and the stochasticity of recombination will generate variation around this expected relationship between $\mathrm{ROH}$ length, recombination rate and time, increasingly so for older coalescent times (Stoffel et al., 2021; Thompson, 2013). Assuming a range of constant mammalian recombination rates (0.649-1.554 cM/Mb) (Dumont \& Payseur, 2008), we estimate that $\mathrm{ROH}<1 \mathrm{Mb}$ in length correspond to haplotypes representing coalescence $>1000$ years ago, whilst $\mathrm{ROH}$ longer than $2 \mathrm{Mb}$ are estimated to result from inbreeding during the past millennium (Figure S8). Furthermore, these estimates of the timing of coalescence of $\mathrm{ROH}$ should be reconsidered when recombination maps are developed for the killer whale genome assembly, as recombination cold or hotspots could fall outside the mean recombination rates used in these estimates.

\subsection{The effect of admixture on $\mathrm{ROH}$}

Genomes sampled at low latitudes, where killer whales are found at low density, were typically characterised as being less autozygous than those sampled at high latitudes (Figure 3; Figure S7). Admixture between lineages with divergent evolutionary histories, and therefore distinct genetic backgrounds, is predicted to break up $\mathrm{ROH}$, through the recombination of different haplotypes (Ceballos, Joshi, et al., 2018). For example, comparison of patterns of $\mathrm{ROH}$ in a global data set of human genomes found that African Americans had notably shorter mean $\mathrm{ROH}$ length than most Europeans or Africans (Pemberton et al., 2012). Our interpretation of the PSMC plot generated from the Antarctic Peninsula type A killer whale genome was that the individual had mixed ancestry due to recent admixture between two divergent lineages that shared a common ancestor 1000-2000 generations ago. Accordingly, the genome of this

FIGURE 5 Kernel density (violin) plots of the length of individual ROH in each genome included in the PSMC analyses. White rectangle shows the interquartile range, and the black bar the median of the data. Samples are grouped by PSMC trajectory, so that (a) includes genomes inferred by PSMC to have an ancestral decline in $N_{e}$ deep in their pedigrees (i.e., those from Figure 2a,c), and (b) includes samples with a more stable $N_{\mathrm{e}}$, and the putatively admixed Antarctic Peninsula sample (i.e., those from Figure $2 \mathrm{~b}, \mathrm{~d}$ ) 
6170

WI LEY-MOLECULAR ECOLOGY

FOOTE ET AL.

(a)

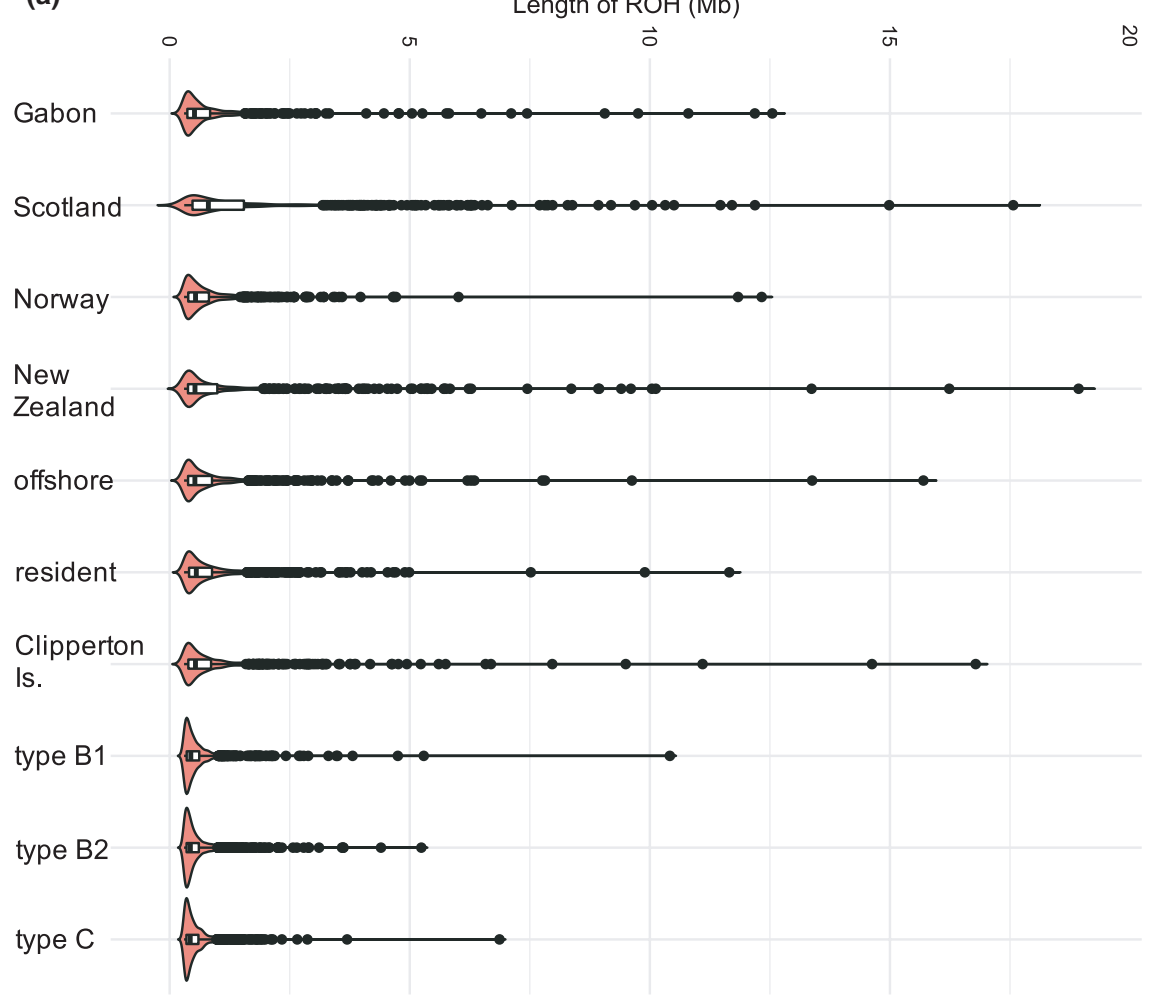

(b)

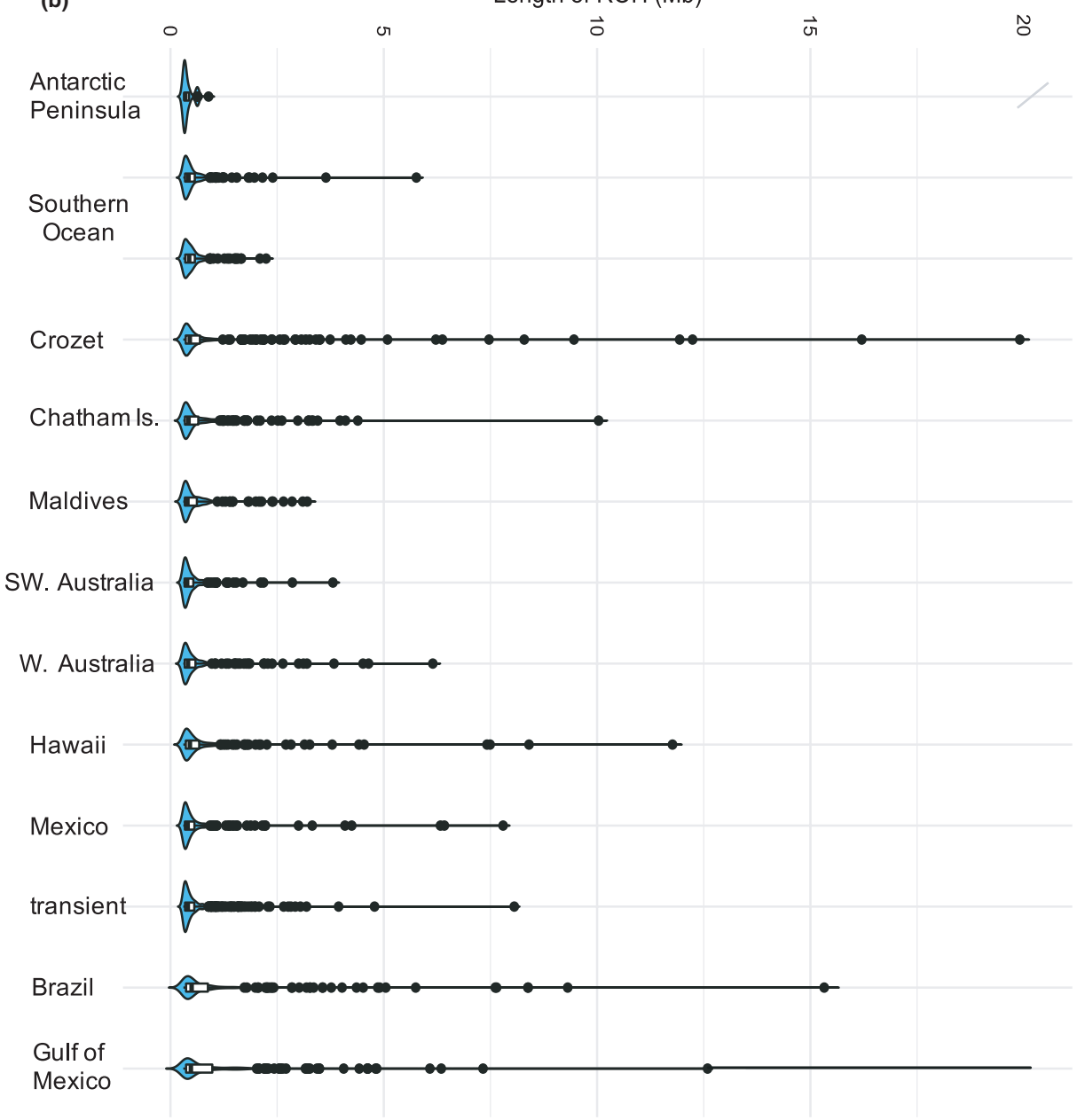

Length of $\mathrm{ROH}(\mathrm{Mb})$

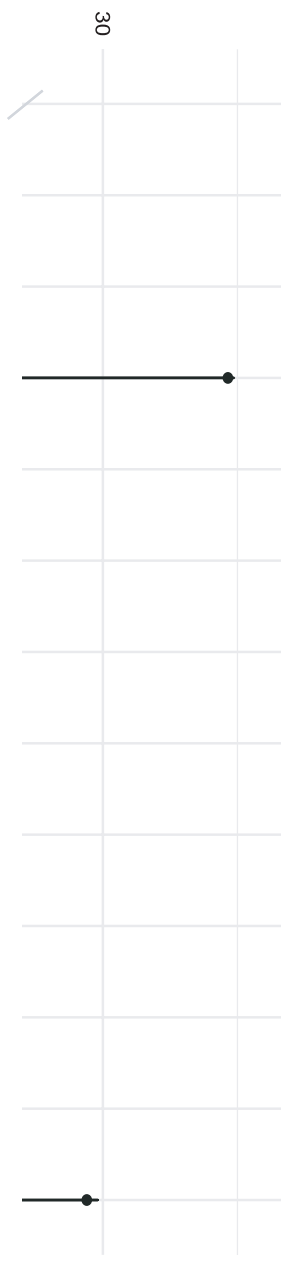


individual had the lowest sum and number of $\mathrm{ROH}$ in the data set. We further illustrate this outcome of episodic admixture of different genetic backgrounds by comparing the $\mathrm{ROH}$ of $\mathrm{F} 1$ offspring from Icelandic and North Pacific transient parents, with the $\mathrm{ROH}$ of the parental lineages (Figure 6; Figure S7). The two admixed individuals show a reduction in longer $(>1 \mathrm{Mb}) \mathrm{ROH}$ relative to the parental lineages.

\subsection{0 | Individual genomic inbreeding coefficients}

Individual genomic inbreeding coefficients were estimated from $\mathrm{ROH}\left(\mathrm{F}_{\mathrm{ROH}}\right)$ as the percentage of the autosomes that are autozygous and in $\mathrm{ROH}>1.5 \mathrm{Mb}$, so as to exclude shorter $\mathrm{ROH}$ which result from background relatedness caused by ancestral bottlenecks, and are thought less likely to reduce individual fitness relative to the population average (i.e., cause inbreeding depression). A geographically widespread set of 21 of the 26 samples had estimated inbreeding coefficients of $\mathrm{F}_{\mathrm{ROH}}>0.015$ (Table S2). Our finding of widespread inbreeding across the species range is consistent with the close kin structure and high social philopatry observed in most killer whale populations studied to date (Baird et al., 2006; Baird \& Whitehead, 2000; Barrett-Lennard, 2000; Beck et al., 2012; Bigg et al., 1990; Busson et al., 2019; Esteban, Verborgh, Gauffier, Giménez, et al., 2016; Ford et al., 2011; Ivkovich et al., 2010; Parsons et al., 2009; Pilot et al., 2010; Reisinger et al., 2017).

When considering the correlation between $\mathrm{NROH}$ and $\mathrm{SROH}$ (Figure 3), a killer whale from a small population studied off the West coast of Scotland was a clear outlier below the regression line, indicating an excess of long $\mathrm{ROH}$ which is consistent with consanguineous mating (Ceballos, Joshi, et al., 2018). We found that $37.8 \%$ of the autosomal regions of the Scottish killer whales' genome was comprised of $\mathrm{ROH}>1.5 \mathrm{Mb}$ (Table S2). The distinct distribution of $\mathrm{ROH}$ lengths in this individual (Figures 3, 4; Figure S7) suggest longterm inbreeding. The genome sampled from the Antarctic Peninsula type A killer whale, and the two captive F1 admixed individuals with
FIGURE 6 (a) Kernel density (violin) plots of the Atlantic (Icelandic) and Pacific (transient) parental genomes and two F1 Iceland-transient admixed individuals bred in captivity. White rectangle shows the interquartile range, and the black bar the median of the data. (b) Schematic diagram of a ROH due to two IBD tracts (blue lines) in a diploid genome sampled from lineage $A$. In the next generation, the tract is in a heterozygous state after recombination with a divergent haplotype due to admixture with lineage B. After $x$ subsequent generations, the $\mathrm{ROH}$ is either further broken up by recombination if subsequent recombination from generations F1 to Fx occur within lineage $B$. If instead the F1 mates within lineage $A$ then the F2 offspring could inherit the blue IBD tract from both parents, re-establishing the same $\mathrm{ROH}$ within the F2 generation (see for example Hasselgren et al., 2021; Robinson et al., 2019) (a)

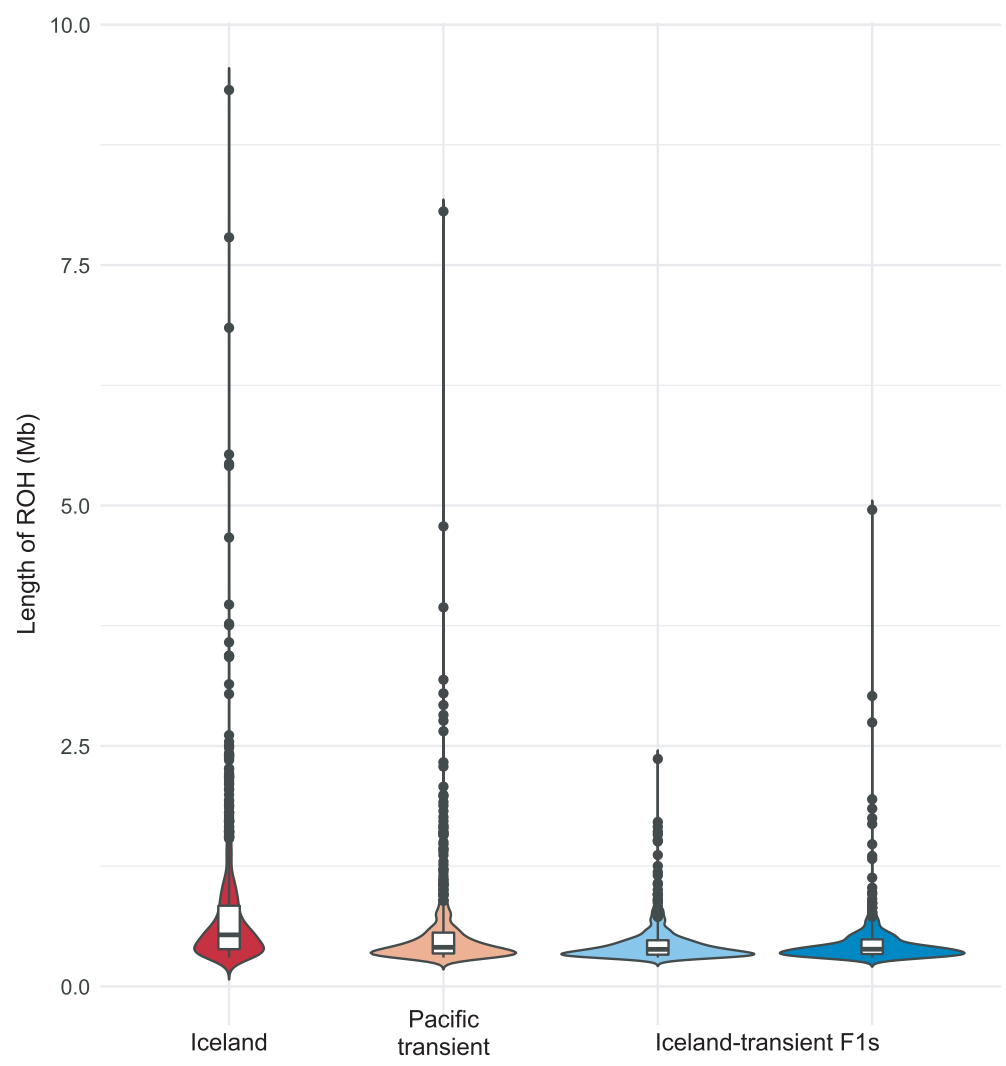

(b)
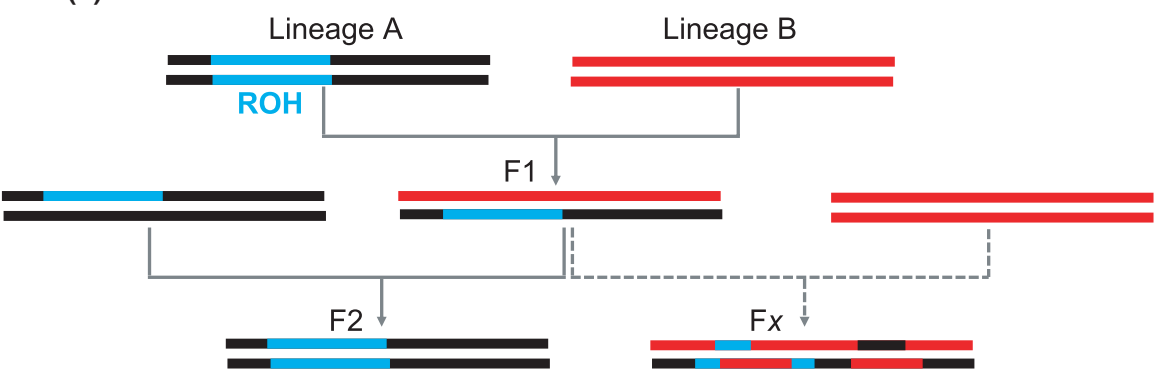
mixed Atlantic and Pacific killer whale parentage (Table S2), highlight the low $\mathrm{F}_{\mathrm{ROH}}$ inbreeding coefficients in admixed genomes, where long $\mathrm{ROH}$ are broken up by the lack of identical by descent haplotypes shared by the two divergent parental lineages.

\subsection{1 | Correlates of runs of homozygosity}

Although short $\mathrm{ROH}(<1 \mathrm{Mb})$ were found in higher abundance in a subset of genomes sampled at high latitude, the relationship between the sum of $<1 \mathrm{Mb} \mathrm{ROH}$ and latitude was not significant correlated (Spearman correlation $\rho=0.30, p=0.13$ ). We therefore fitted general linear models in base $\mathrm{R}$ to test whether latitude or demography (as a categorical variable of either a demographic decline during the last glacial period, or stable demography during that same period) are predictors of the sum of $\mathrm{ROH}<1 \mathrm{Mb}$ and $>2 \mathrm{Mb}$. Whilst latitude did not significantly predict the sum of short $\mathrm{ROH}(<1 \mathrm{Mb})$ per genome ( $t=0.294, p=0.771)$, demography was a significant predictor ( $t=-3.156, p=0.005$; for a single term model $p=0.00229$ ). Neither demography nor latitude predicted the sum of long (>2 Mb) $\mathrm{ROH}$ when compared together in a GLM, but demography was a marginally significant predictor in a single term model $(p=0.0345)$.

\section{4 | DISCUSSION}

We find that the present-day genetic variation and diversity within and among killer whale genomes sampled across the globe was shaped by ancestral demography, hundreds to thousands of generations ago. Killer whales have radiated globally in a timescale comparable to anatomically modern humans. In this study, we have shown that, like human populations that expanded out of Africa (Ceballos, Joshi, et al., 2018; Li \& Durbin, 2011; Pemberton et al., 2012), present day killer whale populations at the edge of the species' range also share the genomic footprints of past demographic history. In a subset of genomes from high latitude populations, we found increasing coalescence in a common ancestor deep in the pedigree of these individuals, inferred by PSMC as declining $N_{\mathrm{e}}$ through the last glacial period, and resulting in many short $\mathrm{ROH}$ in these genomes.

Our findings from a global data set of genomes reinterpret previous inference based upon just two genomes; this earlier study interpreted this sparse data as evidence for a widespread genetic bottleneck across most of the species range during the LGM (Moura et al., 2014). Our results are instead consistent with the scenario suggested by Hoelzel et al. (2007), in which distinct genetic bottlenecks occurred in the ancestors of present-day high latitude populations, caused by a continuous range expansion or serial founder effect during the colonisation of emerging habitat post-LGM (Figure 7). This interpretation is supported by observations of these same high latitude populations being the most differentiated based on allele frequencies (Foote et al., 2019; Morin et al., 2015).

Whilst the patterns of coalescence within the genomes of a subset of mainly high latitude killer whales were consistent with founder effects, coalescence rates in much of our genome data set showed were consistent with more stable long-term $N_{\mathrm{e}}$. Notably, we find that all PSMC plots infer an ancestral effective population size of $N_{\mathrm{e}} \approx 5,000$ in deep time (>100,000-200,000 years ago). How do we interpret this aspect of the demographic history of killer whales? The $y$-axis of the PSMC plot is an estimation of $N_{e}$ derived from the rate of coalescence between the two chromosomes of a diploid genome. The basis of the PSMC method (Li \& Durbin, 2011) is provided by the theory of the coalescent process (Hein et al., 2005; Wakeley, 2008), in which the rate of the coalescent process in a Wright-Fisher population is also inversely related to the population size (Charlesworth, 2009). Coalescence rates are thus dependent upon $N_{e}$ but are also influenced by nonpanmictic population structure and selection. Under an $n$-island model of $n$ panmictic populations separated by a fixed rate of migration (Wright, 1931), and where this rate of migration is low, coalescence events between alleles in different island populations will be rare, which will lead to estimates of large coalescent $N_{\mathrm{e}}$ (Li \& Durbin, 2011; Nei \& Takahata, 1993). Low levels of gene flow among demes that retain their relative sizes can equilibrate the allele frequencies, coalescence times and genetic diversity of neutral loci across demes (Charlesworth, 2009). Thus, a single deme can reflect the genetic diversity in a panmictic population with equivalent $N_{\mathrm{e}}$ to the sum of all individual demes in a structured population (Charlesworth, 2009).

Whilst killer whale populations may violate some of the underlying assumptions of these expectations from model populations, low levels of migration among killer whale populations in low density regions appears to retain genetic diversity (estimated as $\theta$ by mIRho and $N_{\mathrm{e}}$ by PSMC in our analyses) across ocean basins. We found evidence of a rare admixture event in the genome of the Antarctic Peninsula "type A" individual, in which inferred $N_{e}$ exponentially increases during the last glacial period and PSMC bootstraps show a wide confidence interval around the median plot. We interpret this result as evidence of rare and recent admixture between two diverged lineages with distinct demographic histories, which are reflected in the distribution of individual bootstraps. We propose these rare admixture events between divergent lineages maintain the "ancestral" or "baseline" $N_{e}$ of $~ 5000$ in our PSMC plots and break up ROH. Admixture between divergent lineages as described above has been proposed to "rescue" populations and reduce the recessive mutation load (dominance heterosis), in particular upon secondary contact after a period of allopatry and when the two admixing populations' demographic histories do not include shared bottlenecks (Bierne et al., 2002; Crow, 1948; Ingvarsson \& Whitlock, 2000; Whitlock et al., 2000).

The physical position of $\mathrm{ROH}$ in the genome were found to overlap in different individuals. $\mathrm{ROH}$ have been found to be more abundant in genomic regions with low recombination rate in other study systems, often associated with strong selection (Kardos et al., 2017; Pemberton et al., 2012). Heterogeneity in genetic diversity across the genomic landscape has been shown to be highly correlated across killer whale populations, through comparison of interdependent variables: nucleotide diversity $(\pi)$, divergence $\left(D_{\mathrm{xy}}\right)$ and differentiation $\left(F_{\mathrm{ST}}\right)$, across 
FIGURE 7 (a) A simple schematic model showing allele frequencies (for two alleles, red and blue) at equilibrium due to low levels of episodic admixture between demes in the core range, whilst alleles drift to extinction or fixation in demes at the range margins due to (b). Serial founder effects or (c) continuous range expansion (adapted from Peischl et al., 2016). Post expansion variation will coalesce in the founder population

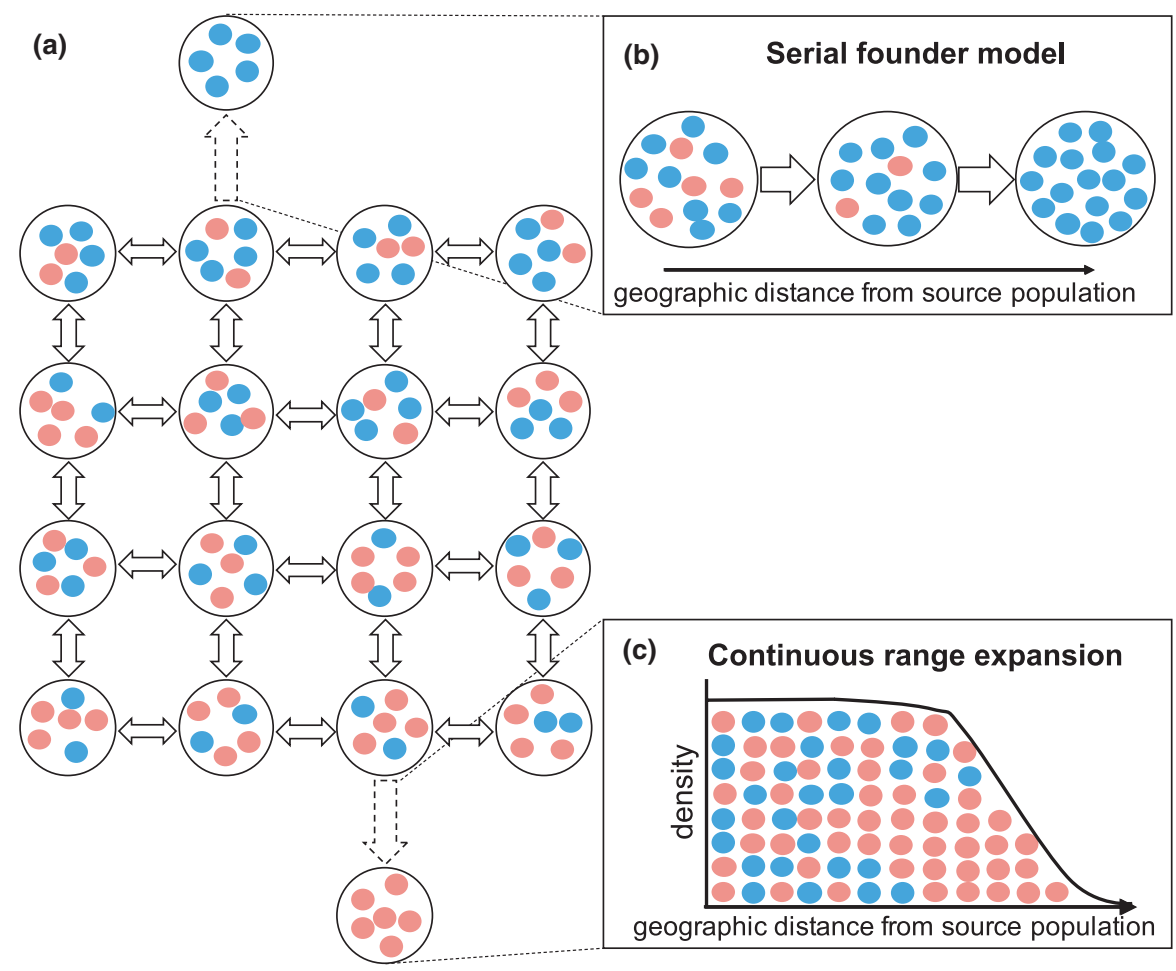

multiple pairwise comparisons (see figure 4 of Foote et al., 2016). Such patterns are typically correlated with the recombination landscape in other study systems (Burri et al., 2015; Samuk et al., 2017); and Foote et al. (2016) concluded that overall the landscape of genomewide differentiation in killer whales is a result of population-specific genetic drift, regionally elevated by ancestral linked selection (e.g., background selection or repeated selective sweeps shared among populations). As such, $N_{e}$ estimates and $\mathrm{ROH}$ density and length will vary with genomic position reflecting the combined changes in population size, population structure and the strength of selection (including background selection) through time (Mather et al., 2020).

The mutation load from post-bottleneck expansion (expansion load) is expected to be comprised of many weakly deleterious recessive mutations in homozygous genotypes, which may have only a small or negligible effect on fitness (Peischl \& Excoffier, 2015), making it difficult to disentangle their impact from extrinsic influences on fitness. Additionally, deleterious recessive mutations within homozygous genotypes become exposed to selection and can be purged over time (Hedrick \& Garcia-Dorado, 2016; Stoffel et al., 2021; Szpiech et al., 2013). Deleterious derived mutations are typically rare (i.e., at low frequency) within populations and are therefore predominantly found in heterozygous genotypes in outbred populations, but in homozygous derived genotypes in inbred populations/ tracts. The fitness of the deleterious mutation in a heterozygous genotype is determined by both the dominance $(h)$ and selection coefficients (s), having fitness ( 1 - hs); whereas in a homozygous genotype, uninfluenced by dominance, fitness is $1-s$ (Huber et al., 2018). Thus, selection will be more efficacious in purging deleterious recessive alleles from $\mathrm{ROH}$ than from heterozygous genotypes. Evidence of such purging has been found by comparing Early Holocene and modern high latitude North Atlantic killer whale genomes (Foote, 2021). Thus, shorter $\mathrm{ROH}$, for example $<1 \mathrm{Mb}$, have typically been subject to more generations of selection (than longer $\mathrm{ROH}$ ), which can act upon deleterious recessive alleles in $\mathrm{ROH}$ through rescue or purging (Stoffel et al., 2021).

However, potential fitness impacts of inbreeding are evident in the small ( $<10$ individuals) Scottish West Coast population, which has had zero recruitment over the past two decades (Beck et al., 2014). The reduction in genetic diversity and individual fitness caused by inbreeding depression can impact population growth and increase the chance of population extinction (Hedrick \& Kalinowski, 2000; Keller \& Waller, 2002). Our finding of $>1.5$ Mb long ROH encompassing a high proportion of the genome combined with the demographic decline in this population suggests the extreme level of long-term inbreeding detected in the Scottish sample exceeds a threshold above which killer whale populations become unviable (see Beck et al., 2014 for consideration of other threats versus inbreeding in this population). Consanguineous mating generates new recessive homozygotes in long $\mathrm{ROH}$, which are in human populations enriched for weakly deleterious alleles (Morton et al., 1956; Szpiech et al., 2013). Yet, even weakly deleterious recessive mutations can contribute to the heritability of complex traits such as genetic diseases and morphology (Lohmueller, 2014). Autosomal recessive disorders, for example Chédiak-Higashi syndrome (Taylor \& Farrell, 1973), have been identified in wild killer whales, but remain under-studied. The genetic impacts of inbreeding depression should therefore be of key concern for populations already impacted by contaminants, depleted prey populations and lethal fishery interactions (Beck et al., 2014; Esteban, Verborgh, Gauffier, Alarcón, et al., 2016; Matkin et al., 2008; Tixier et al., 2017). 
We concur with previous studies (Brüniche-Olsen et al., 2018; Kardos et al., 2016) that $\mathrm{ROH}$ estimated from whole genome sequences can provide more nuanced estimates of genetic diversity than other diversity metrics that do not take contiguity and linkage into account. $\mathrm{ROH}$ provide a means to differentiate IBD coalescing deep in the pedigree due to ancestral demography, versus coalescing in a more recent ancestor. It is the longer, younger $\mathrm{ROH}$ tracts that are likely to harbour more deleterious variation (Stoffel et al., 2021; Szpiech et al., 2013) and which we suggest may be of greater concern when assessing the conservation and management status of endangered populations.

\section{ACKNOWLEDGEMENTS}

The sequencing service was provided by GeneWiz (genewiz.com) and the Genomics Core Facility (GCF), Norwegian University of Science and Technology (NTNU). GCF is funded by the Faculty of Medicine and Health Sciences at NTNU and Central Norway Regional Health Authority. A.D.F. was supported by a short visit grant from the European Science Foundation-Research Networking Programme ConGenOmics and by a Swiss National Science Foundation grant (31003A-143393) to L. Excoffier, and by the European Union's Horizon 2020 research and innovation programme under the Marie Skłodowska-Curie grant agreement No. 663830. MTPG acknowledges ERC Consolidator Award 681396-Extinction Genomics. Additional genomic sequencing was funded by Mridula Srinivasan, Protected Species Science Branch, NOAA Fisheries Office of Science and Technology. We also thank James McBain and Debbie Duffield for providing DNA. We thank Anna Hewett for feedback on our Biorxiv preprint, Marty Kardos and 2 anonymous reviewers for their helpful feedback on an earlier draft submitted to Current Biology, and Martin Stoffel and two anonymous reviewers for their constructive comments on our submission to Molecular Ecology - all of this input greatly improved the manuscript. Marty Kardos also generously provided R-code for estimating the relationship between $\mathrm{ROH}$ length and recombination rate.

\section{AUTHOR CONTRIBUTIONS}

A.D.F. and P.A.M. conceived and coordinated the study. A.D.F. and R.H. analysed the data. A.D.F. wrote the manuscript input from A.A. R.H. L.E., M.T.P.G., J.B.W.W and P.A.M. Samples were provided by R.W.B, C.S.B., L.B., J.B., A.B., T.C., R.C., L.D.R., N.J.D., J.W.D., R.E., T.G., C.G., M.B.H., F.I.P.S., R.d.S., S.B.T., P.T., J.A.T., P.W. DNA extraction, library preparation and sequencing was done by A.D.F, K.R., S.L.F.M., M.D.M., and M.H.S.S. Density maps were provided by K.A.F. Access to reference genome was provided by S.L., G.F., and Y.Z.

\section{DATA AVAILABILITY STATEMENT}

All genomic data and associated metadata have been deposited in the NCBI sequence read archive under BioProjects PRJNA167475, PRJNA531206 and PRJNA236163. BioProject, BioSample and SRA accession numbers for each individual sample associated with this study are given in Table S1.

\section{ORCID}

Andrew D. Foote (D) https://orcid.org/0000-0001-7384-1634 Kelly M. Robertson (D) https://orcid.org/0000-0002-0090-8604

Sara B. Tavares (D) https://orcid.org/0000-0001-7216-6913

Yaolei Zhang (D) https://orcid.org/0000-0003-2131-0254

Phillip A. Morin (D) https://orcid.org/0000-0002-3279-1519

\section{REFERENCES}

Baird, R. W., McSweeney, D. J., Bane, C., Barlow, J., Salden, D. R., La'Ren, A. K., LeDuc, R. G., \& Webster, D. L. (2006). Killer Whales in Hawaiian Waters: Information on population identity and feeding habits. Pacific Science, 60, 523-530. https://doi.org/10.1353/ psc.2006.0024.

Baird, R. W., \& Whitehead, H. (2000). Social organization of mammaleating killer whales: group stability and dispersal patterns. Canadian Journal of Zoology, 78, 2096-2105. https://doi.org/10.1139/ z00-155.

Barrett-Lennard, L. G. (2000). Population structure and mating patterns of killer whales (Orcinus orca) as revealed by DNA analysis. Doctoral dissertation. University of British Columbia.

Bates, D., Maechler, M., Bolker, B., \& Walker, S. (2015). Fitting linear mixed-effects models using Ime4. Journal of Statistical Software, 67, 1-48.

Beck, S., Foote, A. D., Koetter, S., Harries, O., Mandleberg, L., Stevick, P. T., Whooley, P., \& Durban, J. W. (2014). Using opportunistic photo-identifications to detect a population decline of killer whales (Orcinus orca) in British and Irish waters. Journal of the Marine Biological Association of the United Kingdom, 94, 1327-1333.

Beck, S., Kuningas, S., Esteban, R., \& Foote, A. D. (2012). The influence of ecology on sociality in the killer whale (Orcinus orca). Behavioral Ecology, 23(2), 246-253. https://doi.org/10.1093/beheco/arr151.

Bierne, N., Lenormand, T., Bonhomme, F., \& David, P. (2002). Deleterious mutations in a hybrid zone: can mutational load decrease the barrier to gene flow? Genetical Research, 80, 197-204. https://doi. org/10.1017/S001667230200592X.

Bigg, M. A., Olesiuk, P. F., Ellis, G. M., Ford, J. K. B., \& Balcomb, K. C. (1990). Social organization and genealogy of resident killer whales (Orcinus orca) in the coastal waters of British Columbia and Washington State. Report of the International Whaling Commission, 12, 383-405.

Browning, S. R., \& Browning, B. L. (2007). Rapid and accurate haplotype phasing and missing data inference for whole genome association studies by use of localized haplotype clustering. American Journal of Human Genetics, 81, 1084-1097. https://doi.org/10.1086/521987.

Brüniche-Olsen, A., Kellner, K. F., Anderson, C. J., \& DeWoody, J. A. (2018). Runs of homozygosity have utility in mammalian conservation and evolutionary studies. Conservation Genetics, 19, 12951307. https://doi.org/10.1007/s10592-018-1099-y.

Burri, R., Nater, A., Kawakami, T., Mugal, C. F., Olason, P. I., Smeds, L., \& Ellegren, H. (2015). Linked selection and recombination rate variation drive the evolution of the genomic landscape of differentiation across the speciation continuum of Ficedula flycatchers. Genome Research, 25, 1656-1665.

Busson, M., Authier, M., Barbraud, C., Tixier, P., Reisinger, R. R., Janc, A., \& Guinet, C. (2019). Role of sociality in the response of killer whales to an additive mortality event. Proceedings of the National Academy of Sciences, 116, 11812-11817. https://doi.org/10.1073/pnas.18171 74116.

Cahill, J. A., Soares, A. E., Green, R. E., \& Shapiro, B. (2016). Inferring species divergence times using pairwise sequential Markovian coalescent modelling and low-coverage genomic data. Philosophical Transactions of the Royal Society B: Biological Sciences, 371(1699), 20150138. https://doi.org/10.1098/rstb.2015.0138. 
Carøe, C., Gopalakrishnan, S., Vinner, L., Mak, S. S., Sinding, M. H., Samaniego, J. A., Wales, N., Sicheritz-Pontén, T., \& Gilbert, M. T. P. (2018). Single-tube library preparation for degraded DNA. Methods in Ecology and Evolution, 9, 410-419.

Ceballos, F. C., Hazelhurst, S., \& Ramsay, M. (2018). Assessing runs of Homozygosity: A comparison of SNP Array and whole genome sequence low coverage data. BMC Genomics, 19, 106. https://doi. org/10.1186/s12864-018-4489-0.

Ceballos, F. C., Joshi, P. K., Clark, D. W., Ramsay, M., \& Wilson, J. F. (2018). Runs of homozygosity: Windows into population history and trait architecture. Nature Reviews Genetics, 19, 220. https://doi. org/10.1038/nrg.2017.109.

Charlesworth, B. (2009). Effective population size and patterns of molecular evolution and variation. Nature Reviews Genetics, 10(3), 195205. https://doi.org/10.1038/nrg2526.

Chen, I. C., Hill, J. K., Ohlemüller, R., Roy, D. B., \& Thomas, C. D. (2011) Rapid range shifts of species associated with high levels of climate warming. Science, 333, 1024-1026. https://doi.org/10.1126/scien ce.1206432

Crow, J. F. (1948). Alternative hypotheses of hybrid vigour. Genetics, 33, 477-487.

Dumont, B. L., \& Payseur, B. A. (2008). Evolution of the genomic rate of recombination in mammals. Evolution, 62, 276-294. https://doi. org/10.1111/j.1558-5646.2007.00278.x.

Esteban, R., Verborgh, P., Gauffier, P., Alarcón, D., Salazar-Sierra, J. M., Giménez, J., Foote, A. D., \& de Stephanis, R. (2016). Conservation status of killer whales, Orcinus orca, in the Strait of Gibraltar Advances in Marine Biology, 75, 141-172.

Esteban, R., Verborgh, P., Gauffier, P., Giménez, J., Foote, A. D., \& De Stephanis, R. (2016). Maternal kinship and fisheries interaction influence killer whale social structure. Behavioural Ecology and Sociobiology, 70, 111-122. https://doi.org/10.1007/s0026 5-015-2029-3.

Excoffier, L., Dupanloup, I., Huerta-Sánchez, E., Sousa, V. C., \& Foll, M. (2013). Robust demographic inference from genomic and SNP data. PLoS Genetics, 9, e1003905. https://doi.org/10.1371/journ al.pgen.1003905.

Excoffier, L., Foll, M., \& Petit, R. J. (2009). Genetic consequences of range expansions. Annual Review of Ecology, Evolution, and Systematics, 40, 481-501. https://doi.org/10.1146/annurev.ecols ys.39.110707.173414

Foote, A. D., Kaschner, K., Schultze, S. E., Garilao, C., Ho, S. Y. W., Post, K., Higham, T. F. G., Stokowska, C., van der Es, H., Embling, C. B., Gregersen, K., Johansson, F., Willerslev, E., \& Gilbert, M. T. P. (2013). Ancient DNA reveals that bowhead whale lineages survived Late Pleistocene climate change and habitat shifts. Nature Communications, 4, 1-7. https://doi.org/10.1038/ncomms2714.

Foote, A. D., Liu, Y., Thomas, G. W. C., Vinař, T., Alföldi, J., Deng, J., Dugan, S., van Elk, C. E., Hunter, M. E., Joshi, V., Khan, Z., Kovar, C., Lee, S. L., Lindblad-Toh, K., Mancia, A., Nielsen, R., Qin, X., Qu, J., Raney, B. J., ... Gibbs, R. A. (2015). Convergent evolution of the genomes of marine mammals. Nature Genetics, 47, 272. https://doi. org/10.1038/ng.3198.

Foote, A. D., Martin, M. D., Louis, M., Pacheco, G., Robertson, K. M., Sinding, M. H. S., Amaral, A. R., Baird, R. W., Baker, C. S., Ballance, L., Barlow, J., Brownlow, Andrew, Collins, Tim, Constantine, Rochelle, Dabin, Willy, Rosa, Luciano Dalla, Davison, Nicholas J., Durban, John W., Esteban, Ruth, ... Morin, Phillip A. (2019). Killer whale genomes reveal a complex history of recurrent admixture and vicariance. Molecular Ecology, 28, 3427-3444.

Foote, A. D., \& Morin, P. A. (2016). Genome-wide SNP data suggest complex ancestry of sympatric North Pacific killer whale ecotypes. Heredity, 117(5), 316. https://doi.org/10.1038/hdy.2016.54.

Foote, A. D., Vijay, N., Ávila-Arcos, M. C., Baird, R. W., Durban, J. W. Fumagalli, M., Gibbs, R. A., Hanson, M. B., Korneliussen, T. S., Martin, M. D., Robertson, K. M., Sousa, V. C., Vieira, F. G., Vinař
T., Wade, P., Worley, K. C., Excoffier, L., Morin, P. A., Gilbert, M. T. P., \& Wolf, J. B. W. (2016). Genome-culture coevolution promotes rapid divergence of killer whale ecotypes. Nature Communications, 7, 11693. https://doi.org/10.1038/ncomms11693.

Foote, A.D., Gilbert, M.T.P., Gopalakrishnan, S., Louis, M., Martin, M.D., Morin, P.A., Nykänen, M., Scharff-Olsen, C.H., \& Excoffier, L. (2021). Evidence of long-term purging of mutation load in killer whale genomes. Biorxiv, https://doi.org/10.1101/2021.08.21.457186

Ford, M. J., Hanson, M. B., Hempelmann, J. A., Ayres, K. L., Emmons, C. K., Schorr, G. S., Baird, R. W., Balcomb, K. C., Wasser, S. K., Parsons, K. M., \& Balcomb-Bartok, K. (2011). Inferred paternity and male reproductive success in a killer whale (Orcinus orca) population. Journal of Heredity, 102, 537-553. https://doi.org/10.1093/jhered/ esr067.

Forney, K. A., \& Wade, P. R. (2006). World-wide abundance and density of killer whales. Whales, Whaling and Ecosystems (pp. 143-160). University of California Press.

Gutenkunst, R. N., Hernandez, R. D., Williamson, S. H., \& Bustamante, C. D. (2009). Inferring the joint demographic history of multiple populations from multidimensional SNP frequency data. PLoS Genetics, 5, e1000695. https://doi.org/10.1371/journal.pgen.1000695.

Hasselgren, M., Dussex, N., von Seth, J., Angerbjörn, A., Olsen, R.-A., Dalén, L., \& Norén, K. (2021). Genomic and fitness consequences of inbreeding in an endangered carnivore. Molecular Ecology, 30, 2790-2799. https://doi.org/10.1111/mec.15943.

Haubold, B., Pfaffelhuber, P., \& Lynch, M. (2010). MIRho-a program for estimating the population mutation and recombination rates from shotgun-sequenced diploid genomes. Molecular Ecology, 19, 277284. https://doi.org/10.1111/j.1365-294X.2009.04482.x.

Hedrick, P. W., \& Garcia-Dorado, A. (2016). Understanding inbreeding depression, purging, and genetic rescue. Trends in Ecology \& Evolution, 31, 940-952. https://doi.org/10.1016/j.tree.2016.09.005.

Hedrick, P. W., \& Kalinowski, S. T. (2000). Inbreeding depression in conservation biology. Annual Review of Ecology and Systematics, 31, 139-162. https://doi.org/10.1146/annurev.ecolsys.31.1.139.

Hein, J., Schierup, M. H., \& Wiuf, C. (2005). Gene genealogies, variation and evolution. Oxford University Press.

Hoelzel, A. R., Hey, J., Dahlheim, M. E., Nicholson, C. Burkanov, V., \& Black, N. (2007). Evolution of population structure in a highly social top predator, the killer whale. Molecular Biology and Evolution, 24, 1407-1415. https://doi.org/10.1093/molbev/msm063.

Howrigan, D. P., Simonson, M. A., \& Keller, M. C. (2011). Detecting autozygosity through runs of homozygosity: a comparison of three autozygosity detection algorithms. BMC Genomics, 12(1), 1-15. https://doi.org/10.1186/1471-2164-12-460.

Huber, C. D., Durvasula, A., Hancock, A. M., \& Lohmueller, K. E. (2018). Gene expression drives the evolution of dominance. Nature Communications, 9, 2750. https://doi.org/10.1038/s41467-01805281-7.

Ingvarsson, P. K., \& Whitlock, M. C. (2000). Heterosis increases the effective migration rate. Proceedings of the Royal Society of London, Series B: Biological Sciences, 267, 1321-1326. https://doi.org/10.1098/ rspb.2000.1145.

Ivkovich, T., Filatova, O. A., Burdin, A. M., Sato, H., \& Hoyt, E. (2010). The social organization of resident-type killer whales (Orcinus orca) in Avacha Gulf, Northwest Pacific, as revealed through association patterns and acoustic similarity. Mammalian Biology, 75, 198-210. https://doi.org/10.1016/j.mambio.2009.03.006.

Kardos, M., Qvarnström, A., \& Ellegren, H. (2017). Inferring individual inbreeding and demographic history from segments of identity by descent in Ficedula flycatcher genome sequences. Genetics, 205(3), 1319-1334.

Kardos, M., Taylor, H. R., Ellegren, H., Luikart, G., \& Allendorf, F. W. (2016). Genomics advances the study of inbreeding depression in the wild. Evolutionary Applications, 9, 1205-1218. https://doi. org/10.1111/eva.12414. 
Keller, L. F., \& Waller, D. M. (2002). Inbreeding effects in wild populations. Trends in Ecology and Evolution, 17, 230-241. https://doi. org/10.1016/S0169-5347(02)02489-8.

Kimura, M. (1969). The number of heterozygous nucleotide sites maintained in a finite population due to steady flux of mutations. Genetics, 61, 893-903. https://doi.org/10.1093/genetics/61.4.893.

Kohany, O., Gentles, A. J., Hankus, L., \& Jurka, J. (2006). Annotation, submission and screening of repetitive elements in Repbase: RepbaseSubmitter and Censor. BMC Bioinformatics, 7, 474.

Korneliussen, T. S., Albrechtsen, A., \& Nielsen, R. (2014). ANGSD: Analysis of next generation sequencing data. BMC Bioinformatics, 15, 356. https://doi.org/10.1186/s12859-014-0356-4.

Leitwein, M., Duranton, M., Rougemont, Q., Gagnaire, P. A., \& Bernatchez, L. (2020). Using haplotype information for conservation genomics. Trends in Ecology \& Evolution, 35, 245-258. https://doi. org/10.1016/j.tree.2019.10.012.

Li, H., \& Durbin, R. (2011). Inference of human population history from individual whole-genome sequences. Nature, 475, 493-496. https:// doi.org/10.1038/nature10231.

Li, H., Handsaker, B., Wysoker, A., Fennell, T., Ruan, J., Homer, N., Marth, G., Abecasis, G., \& Durbin, R. (2009). The sequence alignment/map format and SAMTOOLs. Bioinformatics, 25(16), 2078-2079. https://doi. org/10.1093/bioinformatics/btp352.

Lohmueller, K. E. (2014). The impact of population demography and selection on the genetic architecture of complex traits. PLoS Genetics, 10, e1004379. https://doi.org/10.1371/journal.pgen.1004379.

Lorenzen, E. D., Nogués-Bravo, D., Orlando, L., Weinstock, J., Binladen, J., Marske, K. A., Ugan, A., Borregaard, M. K., Gilbert, M. T. P., Nielsen, R., Ho, S. Y. W., Goebel, T., Graf, K. E., Byers, D., Stenderup, J. T., Rasmussen, M., Campos, P. F., Leonard, J. A., Koepfli, K.-P., ... Willerslev, E. (2011). Species-specific responses of Late Quaternary megafauna to climate and humans. Nature, 479, 359-364. https:// doi.org/10.1038/nature10574.

Louis, M., Skovrind, M., Samaniego Castruita, J. A., Garilao, C., Kaschner, K., Gopalakrishnan, S., Haile, J. S., Lydersen, C., Kovacs, K. M., Garde, E., Heide-Jørgensen, M. P., Postma, L., Ferguson, S. H., Willerslev, E., \& Lorenzen, E. D. (2020). Influence of past climate change on phylogeography and demographic history of narwhals, Monodon monoceros. Proceedings of the Royal Society B, 287, 20192964.

Lynch, M. (2008). Estimation of nucleotide diversity, disequilibrium coefficients, and mutation rates from high-coverage genomic-sequencing projects. Molecular Biology and Evolution, 25, 2409-2419.

Mather, N., Traves, S. M., \& Ho, S. Y. (2020). A practical introduction to sequentially Markovian coalescent methods for estimating demographic history from genomic data. Ecology and Evolution, 10(1), 579-589. https://doi.org/10.1002/ece3.5888.

Matkin, C. O., Saulitis, E. L., Ellis, G. M., Olesiuk, P., \& Rice, S. D. (2008). Ongoing population-level impacts on killer whales Orcinus orca following the 'Exxon Valdez' oil spill in Prince William Sound, Alaska. Marine Ecology Progress Series, 356, 269-281. https://doi. org/10.3354/meps07273.

Morin, P. A., Archer, F. I., Foote, A. D., Vilstrup, J., Allen, E. E., Wade, P., Durban, J., Parsons, K., Pitman, R., Li, L., Bouffard, P., Abel Nielsen, S. C., Rasmussen, M., Willerslev, E., Gilbert, M. T. P., \& Harkins, T. (2010). Complete mitochondrial genome phylogeographic analysis of killer whales (Orcinus orca) indicates multiple species. Genome Research, 20(7), 908-916. https://doi.org/10.1101/gr.102954.109.

Morin, P. A., Parsons, K. M., Archer, F. I., Ávila-Arcos, M. C., BarrettLennard, L. G., Dalla Rosa, L., Duchêne, S., Durban, J. W., Ellis, G. M., Ferguson, S. H., Ford, J. K., Ford, M. J., Cristina Garilao, M., Gilbert, T. P., Kaschner, K., Matkin, C. O., Petersen, S. D., Robertson, K. M., Visser, I. N., ... Foote, A. D. (2015). Geographic and temporal dynamics of a global radiation and diversification in the killer whale. Molecular Ecology, 24, 3964-3979.

Morton, N. E., Crow, J. F., \& Muller, H. J. (1956). An estimate of the mutational damage in man from data on consanguienous marriages.
Proceedings of the National Academy of Sciences of the United States of America, 42, 855-863.

Moura, A. E., Janse van Rensburg, C., Pilot, M., Tehrani, A., Best, P. B., Thornton, M., Plön, S., de Bruyn, P. J. N., Worley, K. C., Gibbs, R. A., Dahlheim, M. E., \& Hoelzel, A. R. (2014). Killer whale nuclear genome and mtDNA reveal widespread population bottleneck during the last glacial maximum. Molecular Biology and Evolution, 31, 11211131. https://doi.org/10.1093/molbev/msu058.

Nei, M., \& Takahata, N. (1993). Effective population size, genetic diversity, and coalescence time in subdivided populations. Journal of Molecular Evolution, 37, 240-244. https://doi.org/10.1007/BF001 75500.

North, H. L., McGaughran, A., \& Jiggins, C. (2021). Insights into species from whole-genome resequencing. Molecular Ecology. This special issue.

Nykänen, M., Kaschner, K., Dabin, W., Brownlow, A., Davison, N. J., Deaville, R., Garilao, C., Kesner-Reyes, K., Gilbert, M. T. P., Penrose, R., Islas-Villanueva, V., Wales, N., Ingram, S. N., Rogan, E., Louis, M., \& Foote, A. D. (2019). Postglacial colonization of northern coastal habitat by bottlenose dolphins: A marine leading-edge expansion? Journal of Heredity, 110(6), 662-674.

Parmesan, C., \& Yohe, G. (2003). A globally coherent fingerprint of climate change impacts across natural systems. Nature, 421, 37-42. https://doi.org/10.1038/nature01286.

Parsons, K. M., Balcomb, K. C. III, Ford, J. K. B., \& Durban, J. W. (2009). The social dynamics of southern resident killer whales and conservation implications for this endangered population. Animal Behaviour, 77, 963-971. https://doi.org/10.1016/j.anbehav.2009.01.018.

Peischl, S., Dupanloup, I., Bosshard, L., \& Excoffier, L. (2016). Genetic surfing in human populations: from genes to genomes. Current Opinion in Genetics \& Development, 41, 53-61. https://doi.org/10.1016/j. gde.2016.08.003.

Peischl, S., \& Excoffier, L. (2015). Expansion load: recessive mutations and the role of standing genetic variation. Molecular Ecology, 24, 2084-2094. https://doi.org/10.1111/mec.13154.

Pemberton, T. J., Absher, D., Feldman, M. W., Myers, R. M., Rosenberg, N. A., \& Li, J. Z. (2012). Genomic patterns of homozygosity on worldwide human populations. American Journal of Human Genetics, 91, 275-292.

Pilot, M., Dahlheim, M. E., \& Hoelzel, A. R. (2010). Social cohesion among kin, gene flow without dispersal and the evolution of population genetic structure in the killer whale (Orcinus orca). Journal of Evolutionary Biology, 23, 20-31.

Purcell, S., Neale, B., Todd-Brown, K., Thomas, L., Ferreira, M. A., Bender, D., Maller, J., Sklar, P., De Bakker, P. I., Daly, M. J., \& Sham, P. C. (2007). PLINK: a tool set for whole-genome association and population-based linkage analyses. The American Journal of Human Genetics, 81, 559-575. https://doi.org/10.1086/ 519795.

Quinlan, A. R., \& Hall, I. M. (2010). BEDTools: a flexible suite of utilities for comparing genomic features. Bioinformatics, 26, 841-842.

R Core Team (2017). R: A language and environment for statistical computing. R Foundation of Statistical Computing. https://www.r-proje ct.org/.

Reisinger, R. R., Beukes, C., Hoelzel, A. R., \& de Bruyn, P. N. (2017). Kinship and association in a highly social apex predator population, killer whales at Marion Island. Behavioral Ecology, 28, 750-759. https://doi.org/10.1093/beheco/arx034.

Ringbauer, H., Novembre, J., \& Steinruecken, M. (2020). Detecting runs of homozygosity from low-coverage ancient DNA. bioRxiv. https:// doi.org/10.1101/2020.05.31.126912

Robinson, J. A., Räikkönen, J., Vucetich, L. M., Vucetich, J. A., Peterson, R. O., Lohmueller, K. E., \& Wayne, R. K. (2019). Genomic signatures of extensive inbreeding in Isle Royale wolves, a population on the threshold of extinction. Science. Advances, 5, eaau0757. https://doi. org/10.1126/sciadv.aau0757. 
Samuk, K., Owens, G. L., Delmore, K. E., Miller, S. E., Rennison, D. J., \& Schluter, D. (2017). Gene flow and selection interact to promote adaptive divergence in regions of low recombination. Molecular Ecology, 26(17), 4378-4390. https://doi.org/10.1111/mec.14226.

Sarabia, C., von Holdt, B., Larrasoaña, J. C., Uríos, V., \& Leonard, J. A. (2021). Pleistocene climate fluctuations drove demographic history of African golden wolves (Canis lupaster). Molecular Ecology, https:// doi.org/10.1111/mec.15784.

Schubert, M., Lindgreen, S., \& Orlando, L. (2016). AdapterRemoval v2: rapid adapter trimming, identification, and read merging. BMC Research Notes, 9, 1-7. https://doi.org/10.1186/s1310 4-016-1900-2.

Smit, A., Hubley, R., \& Green, P. (1996). REPEATMASKER Open-3.0 https:// www.repeatmasker.org.

Sousa, V., \& Hey, J. (2013). Understanding the origin of species with genome-scale data: modelling gene flow. Nature Reviews Genetics, 14, 404-414. https://doi.org/10.1038/nrg3446.

Stoffel, M. A., Johnston, S. E., Pilkington, J. G., \& Pemberton, J. M. (2021). Mutation load decreases with haplotype age in wild Soay sheep. Evolution Letters, 5, 187-195. https://doi.org/10.1002/evl3.229.

Szpiech, Z. A., Xu, J., Pemberton, T. J., Peng, W., Zöllner, S., Rosenberg, N. A., \& Li, J. Z. (2013). Long runs of homozygosity are enriched for deleterious variation. American Journal of Human Genetics, 93, 90 102. https://doi.org/10.1016/j.ajhg.2013.05.003.

Taylor, B. L., Chivers, S. J., Larese, J., \& Perrin, W. F. (2007). Generation length and percent mature estimates for IUCN assessments of cetaceans. NOAA, NMFS, Southwest Fisheries Science Center. Administrative Report LJ-07-01, 21.

Taylor, R. F., \& Farrell, R. K. (1973). Light and electron microscopy of peripheral blood neutrophils in a killer whale affected with ChediakHigashi syndrome. Federation Proceedings, 32, 822a.

Thompson, E. A. (2013). Identity by descent: variation in meiosis, across genomes, and in populations. Genetics, 194, 301-326. https://doi org/10.1534/genetics.112.148825.

Tixier, P., Barbraud, C., Pardo, D., Gasco, N., Duhamel, G., \& Guinet, C. (2017). Demographic consequences of fisheries interaction within a killer whale (Orcinus orca) population. Marine Biology, 164, 170. https://doi.org/10.1007/s00227-017-3195-9.

Veeramah, K. R., \& Hammer, M. F. (2014). The impact of whole-genome sequencing on the reconstruction of human population history. Nature Reviews Genetics, 15, 149-162. https://doi.org/10.1038/ nrg3625.

Wakeley, J. (2008). Coalescent Theory. An Introduction. Ben Roberts.

Watterson, G. (1975). On the number of segregating sites in genetical models without recombination. Theoretical Population Biology, 7, 256-276. https://doi.org/10.1016/0040-5809(75)90020-9.

Whitlock, M. C., Ingvarsson, P. K., \& Hatfield, T. (2000). Local drift load and the heterosis of interconnected populations. Heredity, 84, 452457. https://doi.org/10.1046/j.1365-2540.2000.00693.x.

Wright, S. (1931). Evolution in Mendelian populations. Genetics, 16, $97-$ 159. https://doi.org/10.1093/genetics/16.2.97.

\section{SUPPORTING INFORMATION}

Additional supporting information may be found online in the Supporting Information section.

How to cite this article: Foote, A. D., Hooper, R., Alexander, A., Baird, R. W., Baker, C. S., Ballance, L., Barlow, J., Brownlow, A., Collins, T., Constantine, R., Dalla Rosa, L., Davison, N. J., Durban, J. W., Esteban, R., Excoffier, L., Martin, S. L. F., Forney, K. A., Gerrodette, T., Gilbert, M. T. P., ... Morin, P. A. (2021). Runs of homozygosity in killer whale genomes provide a global record of demographic histories. Molecular Ecology, 30, 6162-6177. https://doi.org/10.1111/mec.16137 